Ákos Szabó, György Bencskó, Györgyi Szarka, Béla Iván

Thermoresponsive UCST-type behaviour of interpolymer complexes of poly(ethylene glycol) and poly(poly(ethylene glycol) methacrylate) brushes with poly(acrylic acid) in isopropanol MACROMOLECULAR CHEMISTRY AND PHYSICS 218: Paper 1600466. (2017)

DOI: $10.1002 /$ macp.

Full Paper

\title{
Thermoresponsive UCST-type behaviour of interpolymer complexes of poly(ethylene glycol) and poly(poly(ethylene glycol) methacrylate) brushes with poly(acrylic acid) in isopropanol
}

\author{
Ákos Szabó,* György Bencskó, Györgyi Szarka, Béla Iván*
}

\begin{abstract}
Dr. Á. Szabó, Gy. Bencskó, Dr. Gy. Szarka, Prof. B. Iván
Research Centre for Natural Sciences of the Hungarian Academy of Sciences, Institute of Materials and Environmental Chemistry, Polymer Chemistry Research Group, Magyar tudósok krt. 2., H-1117 Budapest, Hungary

E-mail: szabo.akos@ttk.mta.hu
\end{abstract}

UCST-type thermoresponsive behaviour of poly(ethylene glycol)-poly(acrylic acid) (PEGPAA) and poly(poly(ethylene glycol) methacrylate)-poly(acrylic acid) (PPEGMA-PAA) interpolymer complexes has been observed in isopropanol. For these investigations, PPEGMA and PAA with various average molecular weights have been synthesized by atom transfer radical polymerization (ATRP). It has been found that both the PEG and PPEGMA have lower cloud point temperatures $\left(T_{\mathrm{cp}}\right)$ than its mixed polymer solutions with PAA, whereas PAA does not show such behaviour in the investigated temperature range. These findings indicate the reversible formation of interpolymer complexes with variable structure and composition in the solutions of the polymer mixtures in isopropanol. Increasing the ethylene glycol / acrylic acid (EG/AA) molar ratio or the molecular weight of either the PAA or the H-acceptor PEG component of the interpolymer complexes increases the UCST-type cloud point temperatures of these interpolymer systems. The polymer-polymer interactions by hydrogen bonds between 
PAA and PEG or PPEGMA and the correlations between $T_{\mathrm{cp}}$ and structural parameters of the components revealed in the course of these investigations may be utilized for exploring welldefined UCST-type material systems for various applications.

FIGURE FOR ToC_ABSTRACT
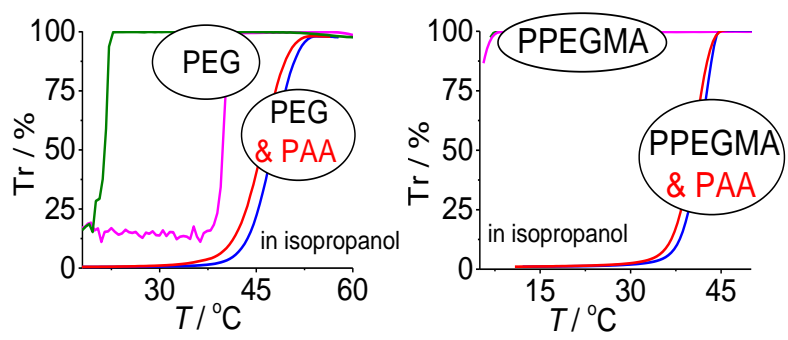


\section{Introduction}

Supramolecular chemistry is a rapidly developing field because investigations on supramolecular systems, i.e. molecular assemblies formed by non-covalent intermolecular bonds, can result in a variety of new materials and in better understanding of the responsive behaviour of biological systems. ${ }^{[1-3]}$ Undoubtly, hydrogen bond is one of the major types of the non-covalent interactions, which has an enormous role in living systems, especially in DNA, RNA and proteins. However, not only intramolecular but intermacromolecular hydrogen bonds can also be used to form novel synthetic polymeric systems, such as self-healing materials ${ }^{[4]}$, controlled drug release systems ${ }^{[5-7]}$ or layer-by-layer (LbL) films. ${ }^{[8]}$ For innovative solutions of a variety of novel technical challenges, such materials with potential of dynamic, stimuliresponsive (smart, intelligent, adaptive) behaviour are required. The most studied environmental parameter applied as regulator of the properties of responsive macromolecular materials is temperature since the group of thermoresponsive polymers is quite a large family. Although the thermoresponsive behaviour was studied mostly in aqueous solutions, organic solvents, such as alcohols, can also be an appropriate choice for many potential applications. ${ }^{[9]}$ In alcohols, the thermoresponsive properties can be regulated with the choice of the solvent, i.e. with the length of the alkyl chain, for a given system, ${ }^{[10]}$ and chemical modifications can also be performed which cannot be achieved in aqueous environment. Thermoresponsiveness in alcoholic environment was studied for example for comb-like poly(poly(ethylene glycol) methacrylate)s and upper critical solution temperature (UCST) type behaviour was observed for this macromolecular family. ${ }^{[11-14]}$ As investigations of thermoresponsive polymers became more and more widespread, the scientific interest turned also to the thermoresponsive behaviour of more complex supramolecular systems, such as polymer complexes (see e.g. Refs. [1-3], [15-33] and references therein). Although the investigations of interpolymer complexes formed by interpolymer hydrogen bonds were started in the 1960s, and many characteristics of such systems have been exploited since then, ${ }^{[19-26]}$ the thermoresponsive aspect of these materials 
has received significant interest only in the last decade. ${ }^{[27-31]}$ One of the most studied interpolymer complex forming pairs is poly(ethylene glycol) and poly(acrylic acid). The most recent theory of supramolecular systems based on this polymer pair in aqueous environment is reported by Suleimenov et al. ${ }^{[34]}$ They claim the formation of soluble interpolymer complexes which can be imagined as extended, partially ionized polyacid coils dynamically coupled with polyacceptor coils via hydrogen bonds in a given $\mathrm{pH}$ range. This $\mathrm{pH}$ range is between two $\mathrm{pH}$ regimes. In the acidic regime, insoluble interpolymer complex formation occurs, whereas in the basic regime interpolymer hydrogen bonds are suppressed.

Herein, we report on the structural dependence of the cloud point temperature of interpolymer complexes formed between poly(acrylic acid) and poly(ethylene glycol) and between poly(acrylic acid) and poly(poly(ethylene glycol) methacrylate), both of them possessing upper critical solution temperature (UCST) type behaviour in isopropanol.

\section{Experimental Section}

\subsection{Materials}

Poly(ethylene glycol) methacrylate with $300 \mathrm{~g} / \mathrm{mol}_{\left(\mathrm{PEGMA}_{300}\right)}$ and $500 \mathrm{~g} / \mathrm{mol}$ molecular

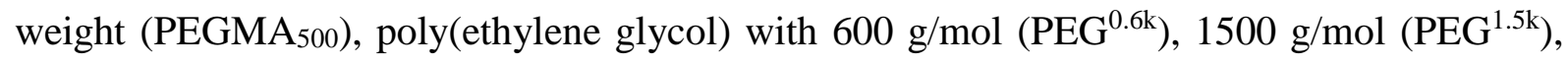
$3400 \mathrm{~g} / \mathrm{mol}\left(\mathrm{PEG}^{3.4 \mathrm{k}}\right)$ and $4600 \mathrm{~g} / \mathrm{mol}\left(\mathrm{PEG}^{4.6 \mathrm{k}}\right)$ number average molecular weight, tert-butyl acrylate $(t \mathrm{BuA}), \mathrm{L}$-ascorbic acid, 1,1,4,7,10,10-hexamethyltriethylenetetraamine (HMTETA) and ethyl 2-bromoisobutyrate were purchased from Sigma-Aldrich, whereas poly(ethylene

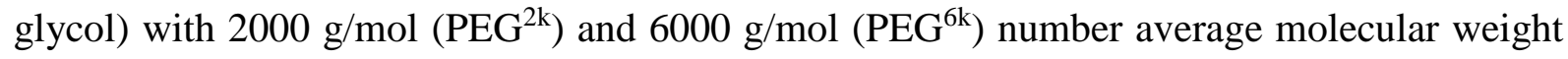
from Fluka. The PEGMAs were purified by passing through a column filled with basic $\mathrm{Al}_{2} \mathrm{O}_{3}$ whereas $t \mathrm{BuA}$ by vacuum distillation before use. $\mathrm{CuCl}$ and $\mathrm{CuBr}$ were stirred with acetic acid overnight followed by washing with abs. ethanol and diethyl ether. Toluene and dichloromethane were distilled over sodium/benzophenone and calcium hydride, respectively. 
Trifluoroacetic acid was purchased from Alpha Aesar whereas isopropanol (2-propanol) and methanol from Molar Chemicals (Hungary) and these were used without further purification.

\subsection{Synthetic procedures}

Poly(acrylic acid)s (PAAs) were prepared by polymerization of $t$ BuA followed by hydrolysis of tert-butyl groups. The hydrolysis was performed using trifluoroacetic acid in dichloromethane at room temperature according to literature procedure ${ }^{[35]}$ followed by drying of the precipitated poly(acrylic acid). Homo- and copolymerizations of PEGMA and $t$ BuA were performed by atom transfer radical polymerization (ATRP) using ethyl 2-bromoisobutyrate as initiator, HMTETA as complexing agent, $\mathrm{CuCl}(\mathrm{PEGMA})^{[36]}$ or $\mathrm{CuBr}(t \mathrm{BuA})$ as catalyst and toluene as solvent. L-ascorbic acid as reducing agent was also added to these reaction mixtures. The molar ratio of the initiator : Cu salt : HMTETA : L-ascorbic acid was $1: 1: 1: 1$ (additional experimental details are described in Supporting Information). The polymerizations were performed under inert atmosphere at $60^{\circ} \mathrm{C}$ for one day. At the end of the reaction, the solutions of the obtained polymers were passed through a column filled with neutral $\mathrm{Al}_{2} \mathrm{O}_{3}$ to remove catalyst, followed by removing of the solvent and drying the polymer in vacuo until constant weight.

\subsection{Measurements}

Number average molecular weights of the synthesized PPEGMA homo- and copolymers were determined by gel permeation chromatography using conventional calibration against polystyrene standards. The gel permeation chromatograph was equipped by three Styragel HR columns, Waters 515 HPLC pump, Waters 717 Autosampler, Jetstream Column Thermostat and Agilent 1260 Infinity refractive index detector applying tetrahydrofuran as eluent with 0.5 $\mathrm{ml} \mathrm{min}{ }^{-1}$ flow rate at $35{ }^{\circ} \mathrm{C} .{ }^{1} \mathrm{H}$ NMR measurements were performed on a Varian $500 \mathrm{MHz}$ spectrometer in $\mathrm{CDCl}_{3}$ or in $\mathrm{D}_{2} \mathrm{O}$. 
PEG-PAA and PPEGMA-PAA blends were prepared by mixing predetermined amounts of homopolymer solutions of $1.0 \mathrm{wt} \%$ in methanol (see Table S1 in Supporting Information) followed by evaporation of methanol. The blends were dissolved in isopropanol or isopropanolmethanol mixtures for turbidity determinations. Transmittance measurements were performed at $500 \mathrm{~nm}$ with a Jasco V-650 spectrophotometer possessing sample holder with temperature controlling. The applied temperature range was $10-70{ }^{\circ} \mathrm{C}$ (heating cycles were measured after the cooling cycles), the heating and cooling rate was $0.5^{\circ} \mathrm{C} \mathrm{min}{ }^{-1}$, and the solutions were stirred with a magnetic stirrer with $60 \mathrm{rpm}$. Inflection points of the polynomials fitted to the obtained transmittance vs. temperature curves were taken as cloud point temperature $\left(T_{\mathrm{cp}}\right)$.

\section{Results and Discussion}

Poly(acrylic acid)s (PAAs) and poly(poly(ethylene glycol) methacrylate)s (PPEGMAs), whose mixed solutions in isopropanol were investigated, were synthesized using atom transfer radical polymerization (ATRP) technique (Figure 1 shows the scheme of the polymerization of a PEGMA macromonomer). For PAA, ATRP of tert-butyl acrylate was performed followed by hydrolysis with trifluoroacetic acid. ${ }^{[35]}$ The occurrence of hydrolysis was proved by ${ }^{1} \mathrm{H}$ NMR spectroscopy (the disappearance of peak of tert-butyl groups at $1.45 \mathrm{ppm}$ indicates the nearly quantitative extent of the hydrolysis) for all of the three synthesized PAA sample (Figure $\mathbf{2 b}$ shows the spectrum of $\mathrm{PAA}^{10.7 \mathrm{k}}$ whereas Figure 2a the spectrum of its initial $\mathrm{P} t \mathrm{BuA}^{19.0 \mathrm{k}}$; the ${ }^{1} \mathrm{H}$ NMR spectra of the other polydonors are displayed in Figure S2-S3 and S5-S6 in the Supporting Information). Gel permeation chromatography data of the initial poly(tert-butyl acrylate)s (Figure S1, S4 and S7 in the Supporting Information) showed that PAAs were prepared with 3300,5800 and $10700 \mathrm{~g} \mathrm{~mol}^{-1}$ number average molecular weights which are abbreviated as $\mathrm{PAA}^{3.3 \mathrm{k}}, \mathrm{PAA}^{5.8 \mathrm{k}}$ and $\mathrm{PAA}^{10.7 \mathrm{k}}$, respectively. The determined number average molecular weight data of the PPEGMA samples are summarized in Table 1, whereas a 
representative gel permeation chromatogram of PPEGMA $500^{9.9 \mathrm{k}}$ is shown in Figure 3 (gel permeation chromatograms of the other synthesized PPEGMA-s are shown in Figure S9, S11, S13, S15, S17 and S19, whereas the ${ }^{1}$ H NMR spectra are displayed in Figure S8, S10, S12, S14, S16, S18 and S20 in the Supporting Information).

a)
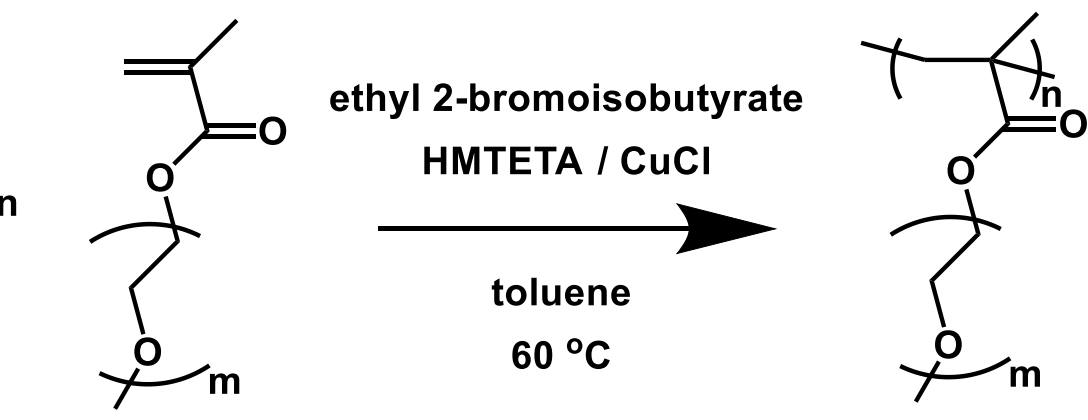

b)
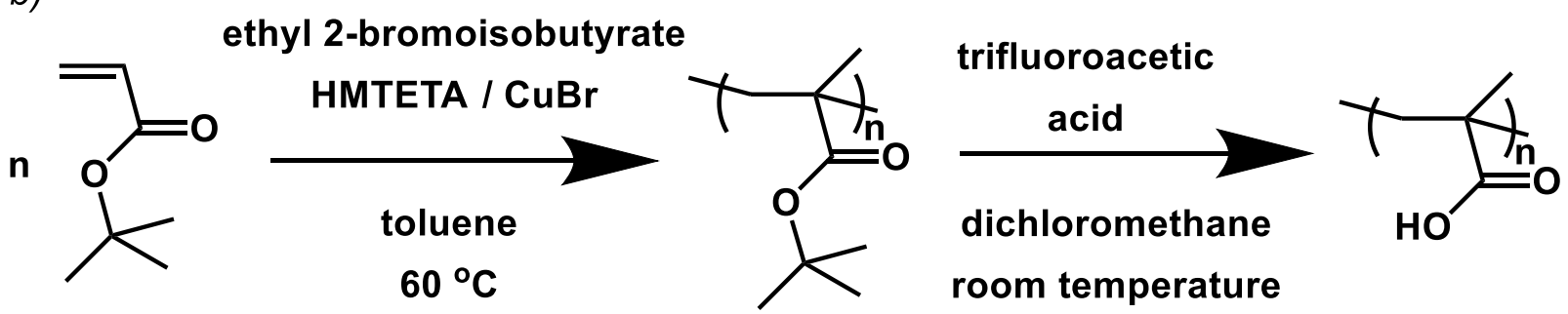

Figure 1. The scheme of the preparation of PPEGMA $(a)$ and PAA $(b)$

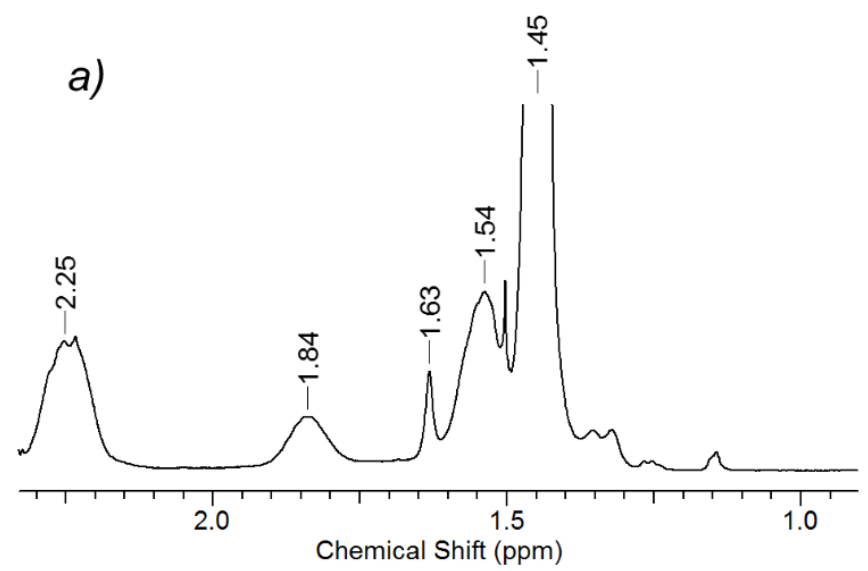




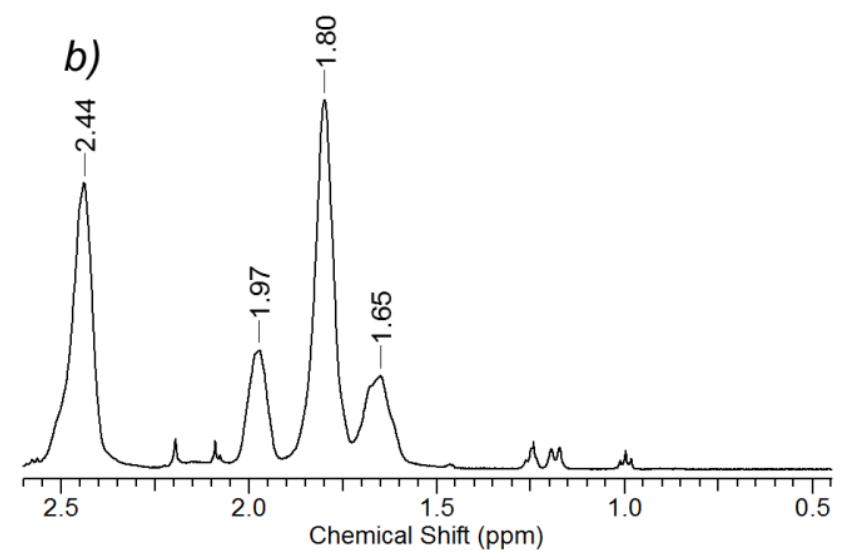

Figure 2. ${ }^{1} \mathrm{H}$ NMR spectra of $\mathrm{P} \mathrm{BuA}^{19.0 \mathrm{k}}$ in $\mathrm{CDCl}_{3}(a)$ and its hydrolyzed form $\mathrm{PAA}^{10.7 \mathrm{k}}$ in $\mathrm{D}_{2} \mathrm{O}(b)$ (peaks at $2.25 \mathrm{ppm}(a)$ and $2.44 \mathrm{ppm}(b)$ are the signals of the methine protons of the polyacrylate main chain, whereas peaks at $1.84 \mathrm{ppm}, 1.63$ and $1.54 \mathrm{ppm}(a)$ and at $1.97 \mathrm{ppm}$, $1.80 \mathrm{ppm}$ and $1.65 \mathrm{ppm}(\mathrm{b})$ belong to the methylene proton of the polyacrylate main chain)

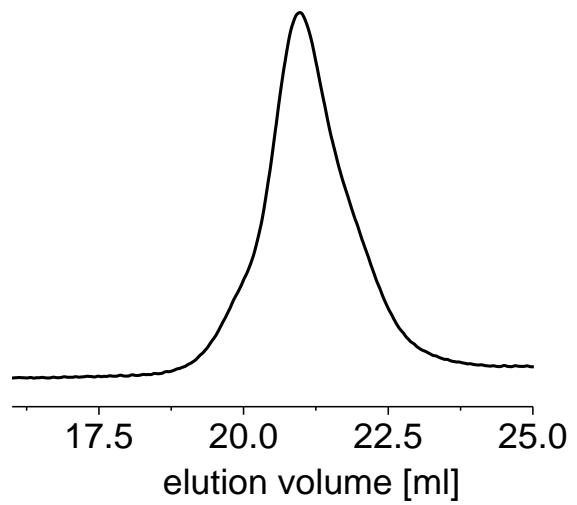

Figure 3. Gel permeation chromatogram of PPEGMA $5009.9 \mathrm{k}$

Table 1. The molar compositions of PEGMA 500 and PEGMA ${ }_{300}$ in the feed for the synthesis of PPEGMA homopolymers and copolymers, and the number average molecular weights $\left(M_{\mathrm{n}}\right)$ and polydispersity indices $\left(M_{\mathrm{w}} / M_{\mathrm{n}}\right)$, determined by gel permeation chromatography, of the resulting PPEGMAs

\begin{tabular}{|c|c|c|c|}
\hline $\begin{array}{c}\text { PEGMA500 } \\
\text { monomeric } \\
\text { unit molar } \\
\text { content } \\
{[\%]}\end{array}$ & $\begin{array}{c}\text { PEGMA300 } \\
\text { monomeric } \\
\text { unit molar } \\
\text { content } \\
{[\%]}\end{array}$ & $\begin{array}{c}\boldsymbol{M}_{\mathbf{n}}(\mathbf{G P C}) \\
{\left[\mathbf{g ~ m o l}^{-1}\right]}\end{array}$ & $\boldsymbol{M}_{\mathbf{w}} / \boldsymbol{M}_{\mathbf{n}}$ \\
\hline 100 & 0 & 3600 & 1.70 \\
\hline 100 & 0 & 9900 & 1.18 \\
\hline 100 & 0 & 10100 & 1.11 \\
\hline 75 & 25 & 10900 & 1.13 \\
\hline 50 & 50 & 12700 & 1.11 \\
\hline
\end{tabular}




\begin{tabular}{|c|c|c|c|}
\hline 25 & 75 & 13800 & 1.20 \\
\hline 0 & 100 & 10400 & 1.34 \\
\hline
\end{tabular}

For studying the thermoresponsive behaviour of PEG-PAA and PPEGMA-PAA interpolymer complexes in aliphatic alcohols, first blends were prepared by mixing given amounts of the 1.0 $\mathrm{wt} \%$ homopolymer solutions in methanol followed by evaporation of this solvent (the prepared blends are summarized in Table S1 in Supporting Information). Then the resulting blends were dissolved in isopropanol or isopropanol-methanol mixtures as solvents. The observation that PAA does not dissolve in isopropanol at the applied concentration, but the blends do, indicates that there is an interaction between PEG or PPEGMA and PAA. The cloud point temperatures $\left(T_{\mathrm{cp}}\right)$ of the complex solutions were determined by measuring the transmittance of the resulting solutions at $500 \mathrm{~nm}$ as a function of the temperature.

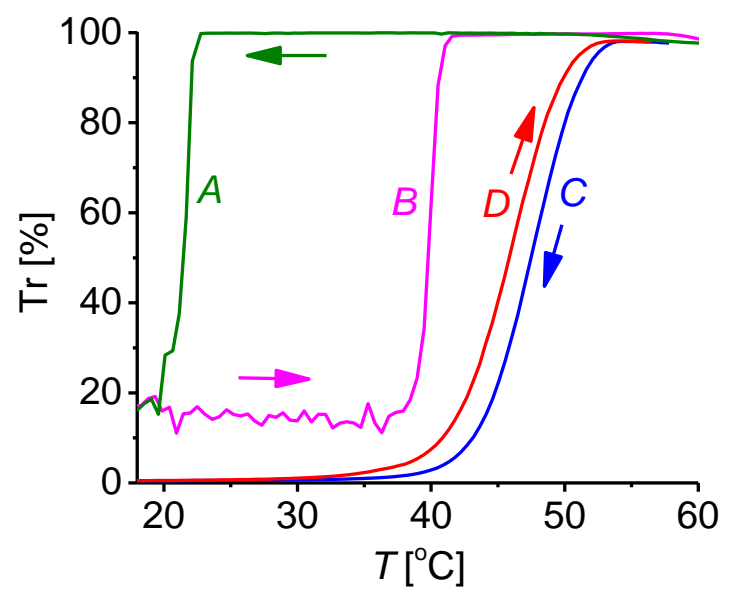

Figure 4. The transmittance (Tr) of $\mathrm{PEG}^{6 \mathrm{k}}$ homopolymer and $\mathrm{PEG}^{6 \mathrm{k}}{ }_{-} \mathrm{PAA}^{10.7 \mathrm{k}}$ solutions in isopropanol at $n(\mathrm{EG}): n(\mathrm{AA})=1.3$ monomeric unit molar ratio with $0.050 \mathrm{wt} \%$ PEG $(A$ and $B)$ and with $0.050 \mathrm{wt} \%$ PEG and $0.0625 \mathrm{wt} \%$ PAA $(C$ and $D)$ concentration as a function of temperature $\left(A: \mathrm{PEG}^{6 \mathrm{k}}\right.$ cooling, $B$ : $\mathrm{PEG}^{6 \mathrm{k}}$ heating, $C$ : $\mathrm{PEG}^{6 \mathrm{k}}{ }_{-} \mathrm{PAA}^{10.7 \mathrm{k}}$ cooling, $D: \mathrm{PEG}^{6 \mathrm{k}}-$ $\mathrm{PAA}^{10.7 \mathrm{k}}$ heating; the arrows indicate the direction of temperature change)

The PEG-PAA interpolymer complexes show reversible phase transition as indicated by a sharp change of transmittance of their isopropanol solution as a function of temperature (Figure 4) in 
the temperature range in which solutions of PAA homopolymers in isopropanol are transparent and do not show phase separation. Although the $\mathrm{PEG}^{6 \mathrm{k}}$ homopolymer solution in isopropanol became opaque by cooling, it has a large hysteresis and the critical temperature of the cooling cycle is significantly lower than that for the $\mathrm{PEG}^{6 \mathrm{k}}-\mathrm{PAA}^{10.7 \mathrm{k}}$ mixed polymer solution. $T_{\mathrm{cp}}$ values are $25^{\circ} \mathrm{C}$ for $\mathrm{PEG}^{6 \mathrm{k}}$ cooling and $39^{\circ} \mathrm{C}$ for $\mathrm{PEG}^{6 \mathrm{k}}$ heating, and $48^{\circ} \mathrm{C}$ for $\mathrm{PEG}^{6 \mathrm{k}}-\mathrm{PAA}$ cooling and $46{ }^{\circ} \mathrm{C}$ for $\mathrm{PEG}^{6 \mathrm{k}}$-PAA heating. This significant difference in the $T_{\mathrm{cp}}$ values indicates considerable interaction between the H-donor carboxylic groups of the acrylic acid monomeric units of PAA and the $\mathrm{H}$-acceptor oxygen atoms of the PEG chains in isopropanol. Such complexes were previously reported in aqueous environments. ${ }^{[19-26]}$ The thermoresponsive behaviour of the PEG-PAA mixed polymer solutions in isopropanol is UCST-type, i.e. the solubility of the polymer blends decreases with decreasing temperature and reaches a critical value at the cloud point temperature below which a separated polymer-rich phase appears due to the presence of interpolymer hydrogen bonds.

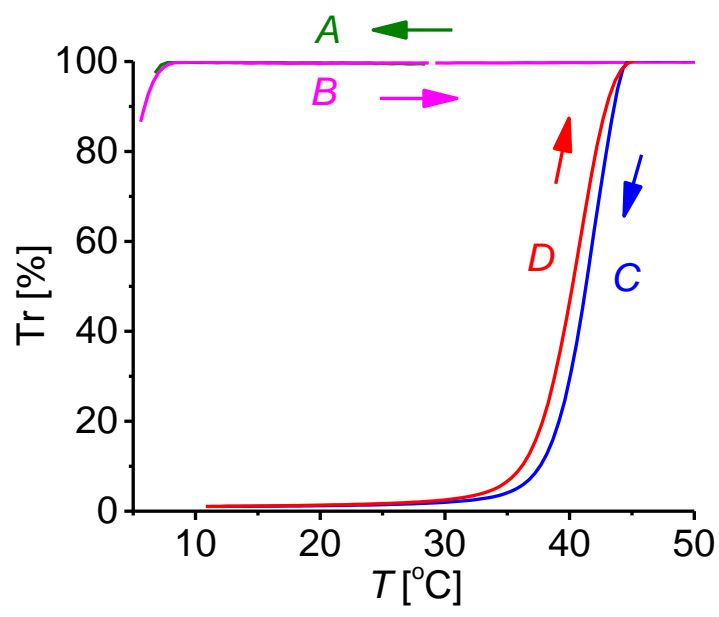

Figure 5. The transmittance (Tr) of PPEGMA ${ }_{500}{ }^{9.9 \mathrm{k}}$ homopolymer and PPEGMA $_{500}{ }^{9.9 \mathrm{k}}$-PAA $^{10.7 \mathrm{k}}$ solutions in isopropanol at $n(\mathrm{EG}): n(\mathrm{AA})=1.3$ monomeric unit molar ratio with $0.0625 \mathrm{wt} \%$ PPEGMA $(A$ and $B)$ and with $0.0625 \mathrm{wt} \%$ PPEGMA and 0.0625 wt $\%$ PAA $(C$ and $D)$ concentration as a function of temperature $\left(A\right.$ : PPEGMA $500{ }^{9.9 \mathrm{k}}$ cooling, $B$ : PPEGMA ${ }_{500}{ }^{9.9 \mathrm{k}}$ heating, $C$ : PPEGMA ${ }_{500}{ }^{9.9 \mathrm{k}}-\mathrm{PAA}^{10.7 \mathrm{k}}$ cooling, $D$ : PPEGMA $500^{9.9 \mathrm{k}}-\mathrm{PAA}^{10.7 \mathrm{k}}$ heating; the arrows indicate the direction of temperature change) 
Reversible phase transition phenomena, analogous to PEG-PAA complexes, were also observed in the case of PPEGMA500-PAA blends dissolved in isopropanol (Figure 5). Since the PPEGMA 500 homopolymer used for blend formation has much lower $T_{\mathrm{cp}}$ (presumably below $\left.5{ }^{\circ} \mathrm{C}\right)$ than the PPEGMA 500 -PAA blend $\left(T_{\mathrm{cp}}=42{ }^{\circ} \mathrm{C}\right.$ for cooling and $T_{\mathrm{cp}}=41{ }^{\circ} \mathrm{C}$ for heating $)$ in this alcoholic environment ${ }^{[11-14]}$, this thermoresponsiveness indicates that PAA can form interpolymer complexes by hydrogen bonds with these comb-like polymacromonomer brushes possessing short PEG side chains in isopropanol similar to poly(vinyl ether)s of ethylene glycol and di(ethylene glycol) as reported earlier ${ }^{37}$.
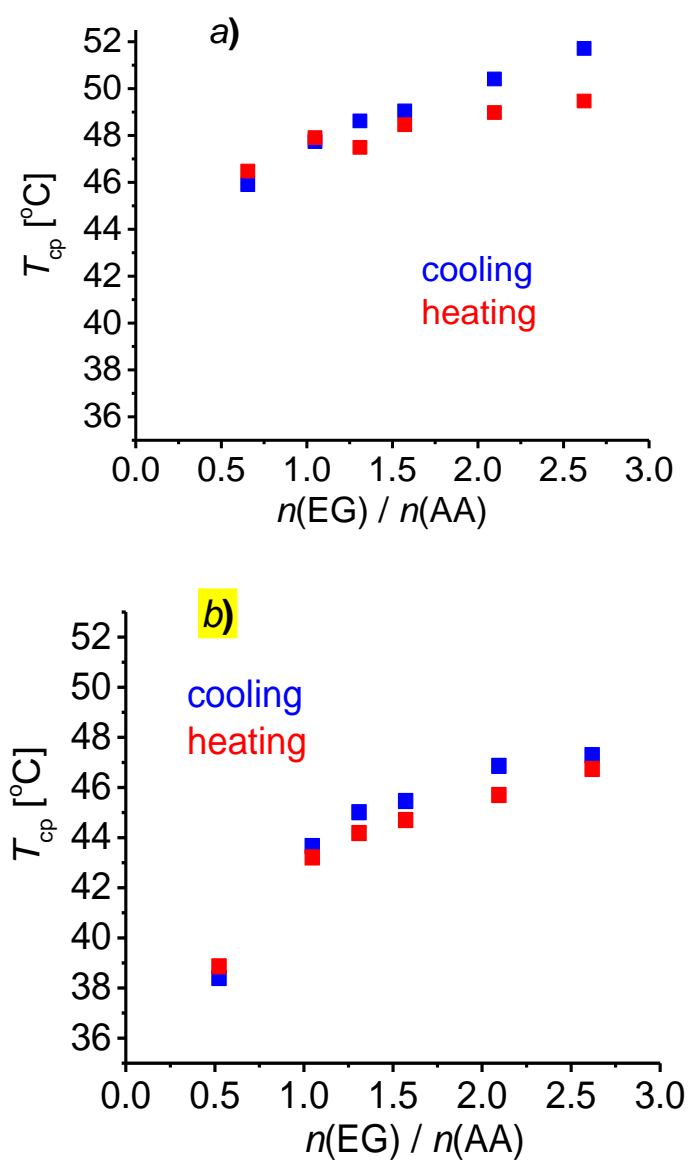

Figure 6. Cloud point temperatures of $\mathrm{PEG}^{6 \mathrm{k}}-\mathrm{PAA}^{10.7 \mathrm{k}}(a)$ and $\mathrm{PPEGMA}_{500}{ }^{9.9 \mathrm{k}}-\mathrm{PAA}^{10.7 \mathrm{k}}(b)$ solutions in isopropanol as a function of EG:AA monomeric unit molar ratios with 0.0625 wt $\%$ PAA concentration 
Figure 6a shows the observed cloud point temperatures of PEG-PAA blends dissolved in isopropanol with different EG:AA monomeric unit molar ratios obtained by varying the added amount of PEG at constant amount of PAA. It can be seen in this figure that with increasing the PEG:PAA ratio, the phase transition temperature $\left(T_{\mathrm{cp}}\right)$ of the interpolymer complexes increases in the investigated ratio range. The fact that the cloud point temperature changes with changing the PEG:PAA ratios indicates that the composition of the interpolymer complexes forming a new polymer-rich phase under $T_{\mathrm{cp}}$ in isopropanol is different depending on the initial blend composition.

Similar changes of the cloud point temperature with blend composition was observed in the case of the PPEGMA-PAA polymer solutions as well (Figure 6b), that is the increase of the $n(\mathrm{EG}): n(\mathrm{AA})$ ratio results in the increase of the $T_{\mathrm{cp}}$. It can also be seen that the extents of hysteresis in the cases of PPEGMA:PAA polymer mixture solutions are somewhat smaller than that in the case of the PEG:PAA polymer mixture solutions.

The tendency that the UCST-type critical temperature of the solubility of the complexes increases with increasing EG:AA monomeric unit molar ratio can be explained by the increasing number of hydrogen bonds with the increasing amount of the EG monomeric units, i.e. with the increasing amount of hydrogen bonded segments in the interpolymer complex. It can be argued that increasing the number of hydrogen bonds will decrease the entropical driving force of mixing with the solvent molecules by decreasing chain flexibility.

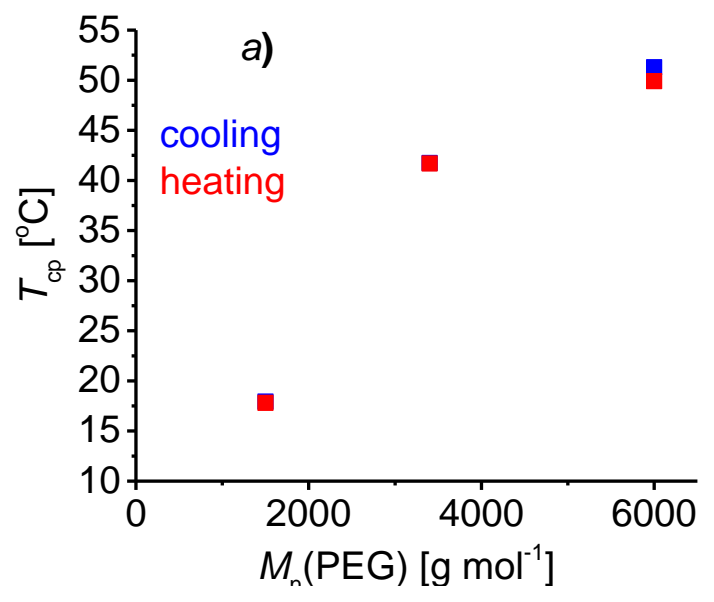




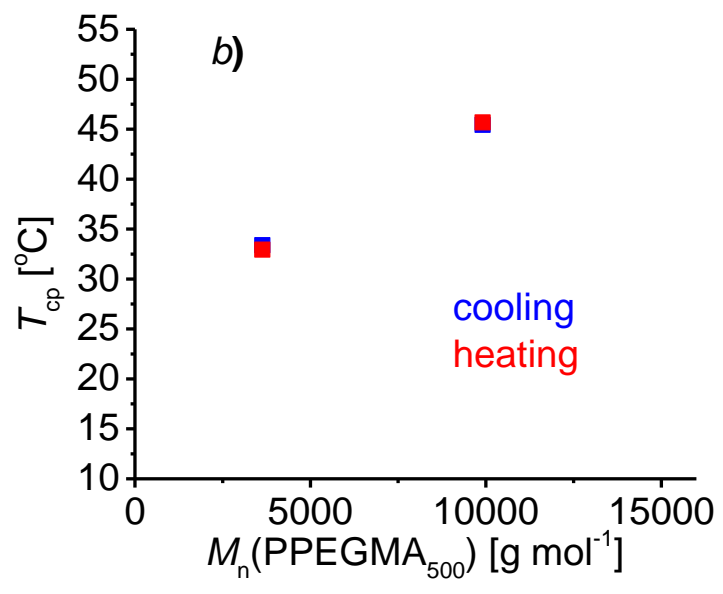

Figure 7. Cloud point temperatures of PEG-PAA ${ }^{10.7 \mathrm{k}}(a)$ and $\operatorname{PPEGMA}_{500}-\mathrm{PAA}^{10.7 \mathrm{k}}(b)$ solutions in isopropanol as a function of PEG $(0.05 \mathrm{wt} \%)(a)$ or PPEGMA $(0.0625 \mathrm{wt} \%)(b)$ molecular weights at $n(\mathrm{EG}): n(\mathrm{AA})=1.3$ monomeric unit molar ratio with $0.0625 \mathrm{wt} \%$ PAA concentration
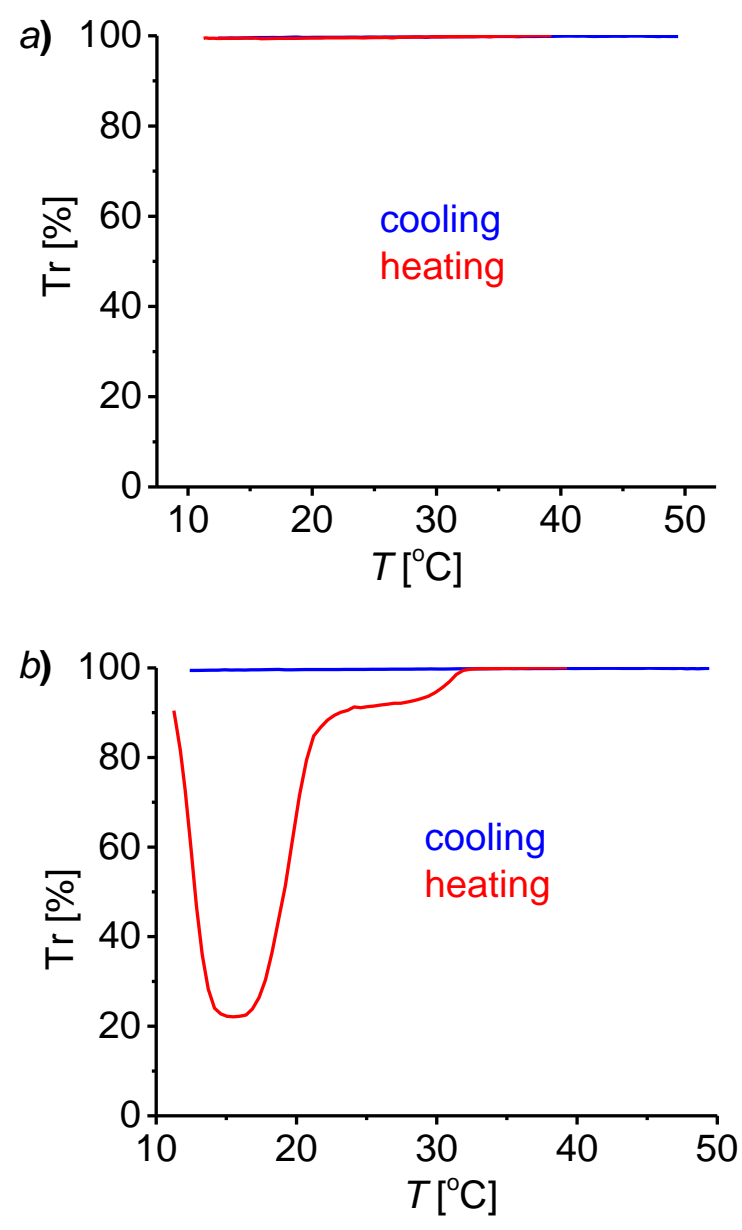
Figure 8. The transmittance (Tr) of $\mathrm{PEG}^{0.6 \mathrm{k}}(a)$ and $\mathrm{PEG}^{1.5 \mathrm{k}}(b)$ homopolymer solutions in isopropanol as a function of temperature (0.05 wt\% PEG concentration)

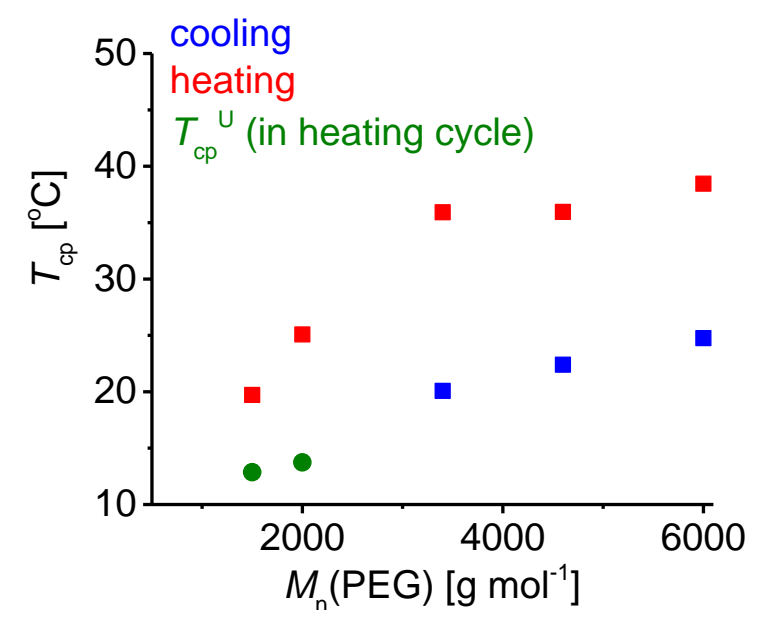

Figure 9. Cloud point temperatures of PEG homopolymer solutions with different molecular weights in isopropanol (0.05 wt\% PEG concentration)

The dependence of cloud point temperatures as a function of the number average molecular weight of the proton acceptor polymers was also studied. For both polymers, PEG and PPEGMA, the cloud point temperatures of the interpolymer complexes in isopropanol decrease with decreasing molecular weight of the H-acceptor PEG chains (Figure 7) which follows the same tendency as observed for the PPEGMA homopolymer in isopropanol. ${ }^{[11]}$ In the case of PEG, a steep decrease of $T_{\mathrm{cp}}$ can be observed under $2000 \mathrm{~g} / \mathrm{mol}$ molecular weight, which could be explained by the cooperativeness, i.e. the occurence of the lower PEG molecular weight limit of the PEG-PAA interpolymer complex formation. ${ }^{[22]}$ However, in order to make relevant conclusions, the transmittance-temperature curves of the PEG homopolymers with different molecular weights in isopropanol were also studied. The investigated PEG samples (measured in the same time) can be sorted into three groups. The low molecular weight polymers, such as $\mathrm{PEG}^{0.6 \mathrm{k}}$, do not show phase separation in isopropanol in the studied temperature interval (Figure 8a). The next group, such as $\mathrm{PEG}^{1.5 \mathrm{k}}$ and $\mathrm{PEG}^{2 \mathrm{k}}$ do not show transmittance decrease in 
the cooling cycle under the applied measurement conditions. However, both $\mathrm{PEG}^{1.5 \mathrm{k}}$ and $\mathrm{PEG}^{2 \mathrm{k}}$ exhibit both LCST-type $\left(T_{\mathrm{cp}}^{\mathrm{L}}\right)$ and UCST-type $\left(T_{\mathrm{cp}}^{\mathrm{U}}\right)$ cloud points, i.e. precipitation at $T_{\mathrm{cp}}{ }^{\mathrm{L}}$ followed by redissolution at $T_{\mathrm{cp}} \mathrm{U}$ is reproducibly observed in the heating cycle (Figure $\mathbf{8 b}$ ). Additional measurements showed that the $T_{\mathrm{cp}}{ }^{\mathrm{L}}$ of these PEG homopolymers in isopropanol is near to the lower limit temperature of the measurements represented in Figure $8 \mathrm{~b}$ indicating that this unexpected phenomenon can be explained by the prolongation of phase separation triggered by cooling. However, $T_{\mathrm{cp}}^{\mathrm{U}}$ of these PEGs is considerable lower than of the higher molecular weight PEGs (Figure 9). The third group contains the higher molecular weight PEGs, $\mathrm{PEG}^{3.4 \mathrm{k}}, \mathrm{PEG}^{4.6 \mathrm{k}}$ and $\mathrm{PEG}^{6 \mathrm{k}}$, which show phase separation in both the cooling and heating cycles (Figure 4$)$. However, $T_{\mathrm{cp}}$ determined from the heating cycle is considerably higher than that observed in the cooling cycle. This is analogues to the results of Ho et al. observed in ethanol ${ }^{38}$, who reported that the resulting polymer-rich phase is crystalline PEG which forms homogeneous phase with the solvent at the nearly molecular weight independent melting temperature, i.e. at $40{ }^{\circ} \mathrm{C}$.

Because the solutions of the PEG-PAA mixtures do not show hysteresis, i.e. considerable difference between the cloud point temperatures in the cooling and heating cycles in the presence of PAA, it can be assumed that interpolymer complexes were formed and precipitated below $T_{\mathrm{cp}}$ instead of precipitation of crystalline PEG homopolymers. The increase of $T_{\mathrm{cp}}$ with increasing PEG molecular weight (Figure 7a) indicates that the length of the PEG chains plays also a crucial role in the formation of the complexes with PAA.

Comparing the diagrams of PEG and PPEGMA containing complexes in Figure $7 \mathrm{a}$ and $7 \mathrm{~b}$, respectively, it can be seen that the $T_{\mathrm{cp}}$ of the PEG complex is a little bit higher than that of the PPEGMA-complex in the same PEG/PPEGMA molecular weight range. This is presumably due to the presence of the polymethacrylate main chains in the latter case which increases its solubility in isopropanol at lower temperatures, on the one hand. On the other hand, with the similar EG:AA monomeric unit molar ratios, the interpolymer complexes with PEG are 
expected to be more compact than complexes with the comb-like PPEGMA containing less accessible $\mathrm{H}$-acceptor EG units close to the main chain.
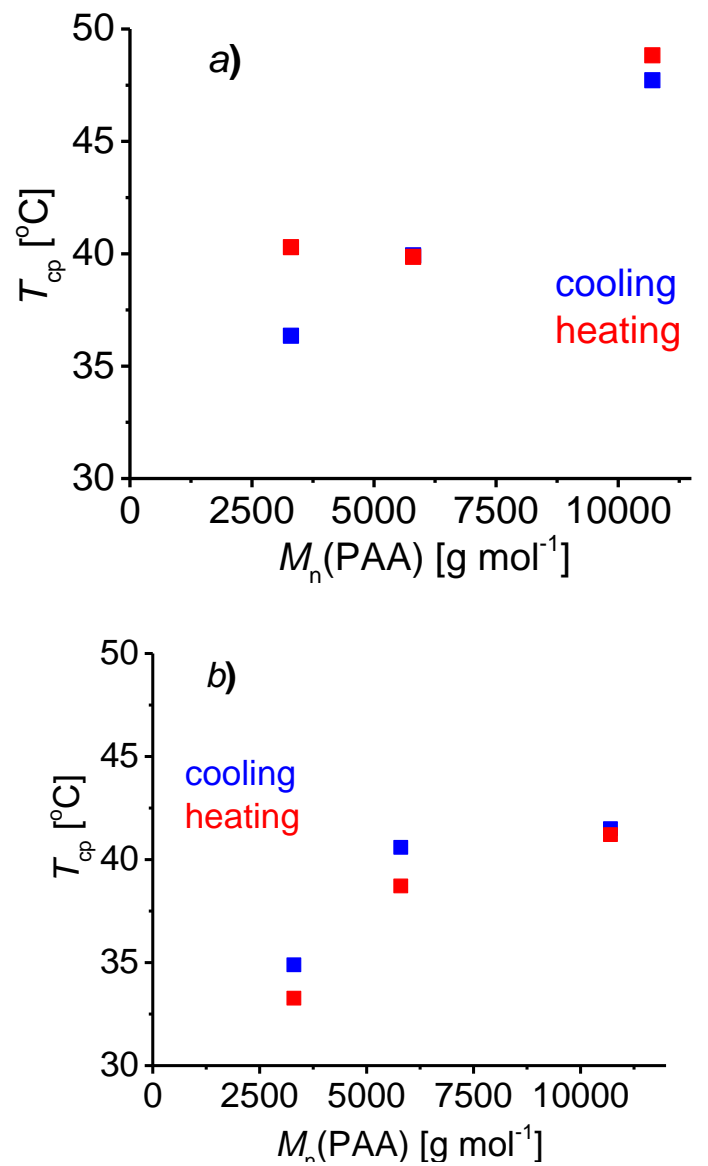

Figure 10. Cloud point temperatures of PEG ${ }^{6 \mathrm{k}}$-PAA $(a)$ and PPEGMA $500{ }^{9.9 \mathrm{k}}$-PAA $(b)$ solutions in isopropanol as a function of PAA molecular weights at $n(\mathrm{EG}): n(\mathrm{AA})=1.3$ monomeric unit molar ratio with $0.0625 \mathrm{wt} \%$ PAA and $0.05 \mathrm{wt} \%$ PEG $(a)$ or $0.0625 \mathrm{wt} \%$

$$
\text { PPEGMA }_{500}(b) \text { concentration }
$$

When the $M_{\mathrm{n}}$ of the proton donor PAA polymer was varied, an increasing tendency of $T_{\mathrm{cp}}$ with both the PEG-PAA and PPEGMA-PAA systems is observed with increasing the polydonor molecular weight (Figure 10a and 10b). In the case of $\mathrm{PEG}^{6 \mathrm{k}}-\mathrm{PAA}^{3.3 \mathrm{k}}$ system the cloud point temperature in the heating cycle is considerably higher than in the cooling cycle (Figure 10a), and it is in the crystal melting range of $\mathrm{PEG}^{6 \mathrm{k}}$ (Figure 4). This phenomenon indicates that PEG crystallization is possible in the presence of low molecular weight PAA, however, the 
association formation is also present since the $\mathrm{PEG}^{6 \mathrm{k}}$ homopolymer forms a new polymer-rich phase only at considerably lower temperature in the cooling cycle.
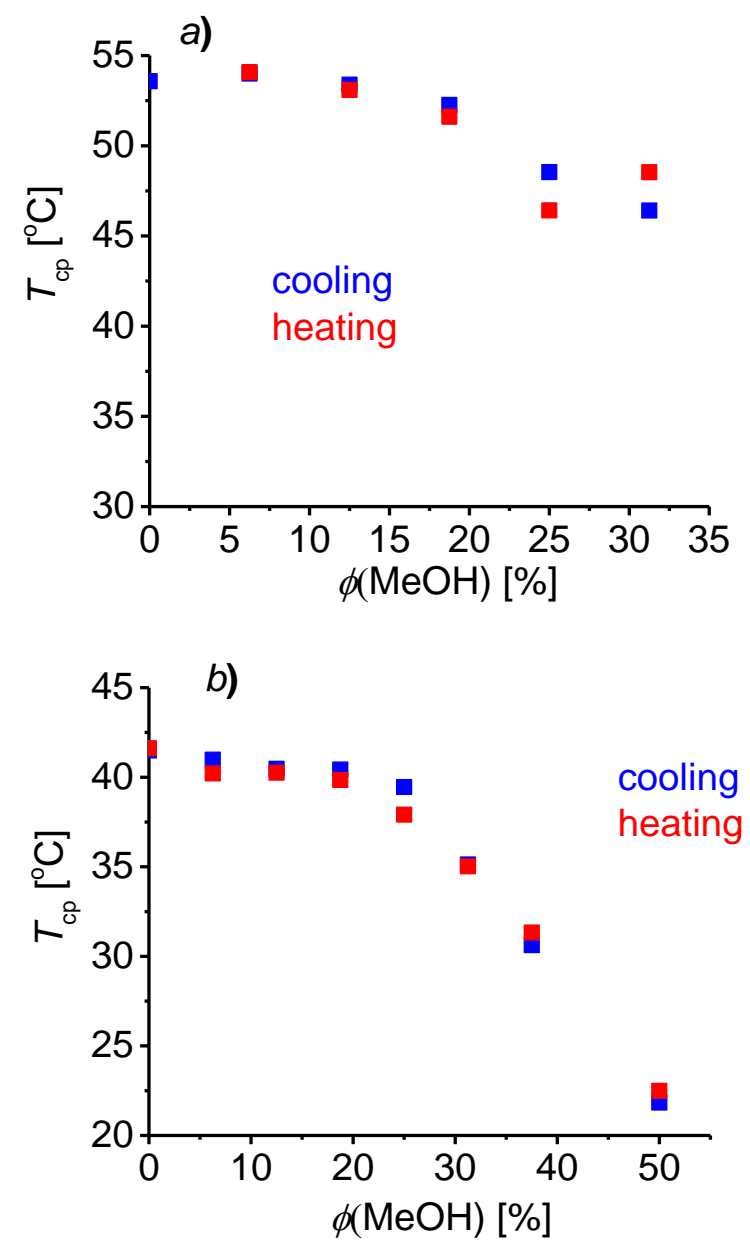

Figure 11. Cloud point temperatures of $\mathrm{PEG}^{6 \mathrm{k}}-\mathrm{PAA}^{10.7 \mathrm{k}}(a)$ and $\mathrm{PPEGMA}_{500}{ }^{9.9 \mathrm{k}}-\mathrm{PAA}^{10.7 \mathrm{k}}(b)$ solutions in isopropanol/methanol solvent mixtures as a function of methanol volume fraction $(\Phi(\mathrm{MeOH}))$ at $n(\mathrm{EG}): n(\mathrm{AA})=1.3$ monomeric unit molar ratio with $0.0625 \mathrm{wt} \% \mathrm{PAA}$ and $0.05 \mathrm{wt} \%$ PEG $(a)$ or $0.0625 \mathrm{wt} \%$ PPEGMA500 $(b)$ concentration

Figure 11a and Figure 11b show the dependence of $T_{\mathrm{cp}}$ of $\mathrm{PEG}^{6 \mathrm{k}}-\mathrm{PAA}^{10.7 \mathrm{k}}$ and PPEGMA $_{500}{ }^{9.9 \mathrm{k}}-\mathrm{PAA}^{10.7 \mathrm{k}}$ on methanol content in methanol-isopropanol solvent mixtures, respectively. Since methanol is a good solvent of the components with the absence of cloud point in the investigated temperature range, it is expected that increasing the methanol content results in increased solubility of the complex, i.e. decrease in the UCST-type cloud point 
temperature. Interestingly, below $20 \mathrm{~V} / \mathrm{V} \%$ methanol content $T_{\mathrm{cp}}$ does not change considerably, and it decreases only above this solvent composition in accordance with expectations. The presence of the plateau at low methanol content indicates that the solubility of the interpolymer complexes does not change with addition of small amount of methanol.
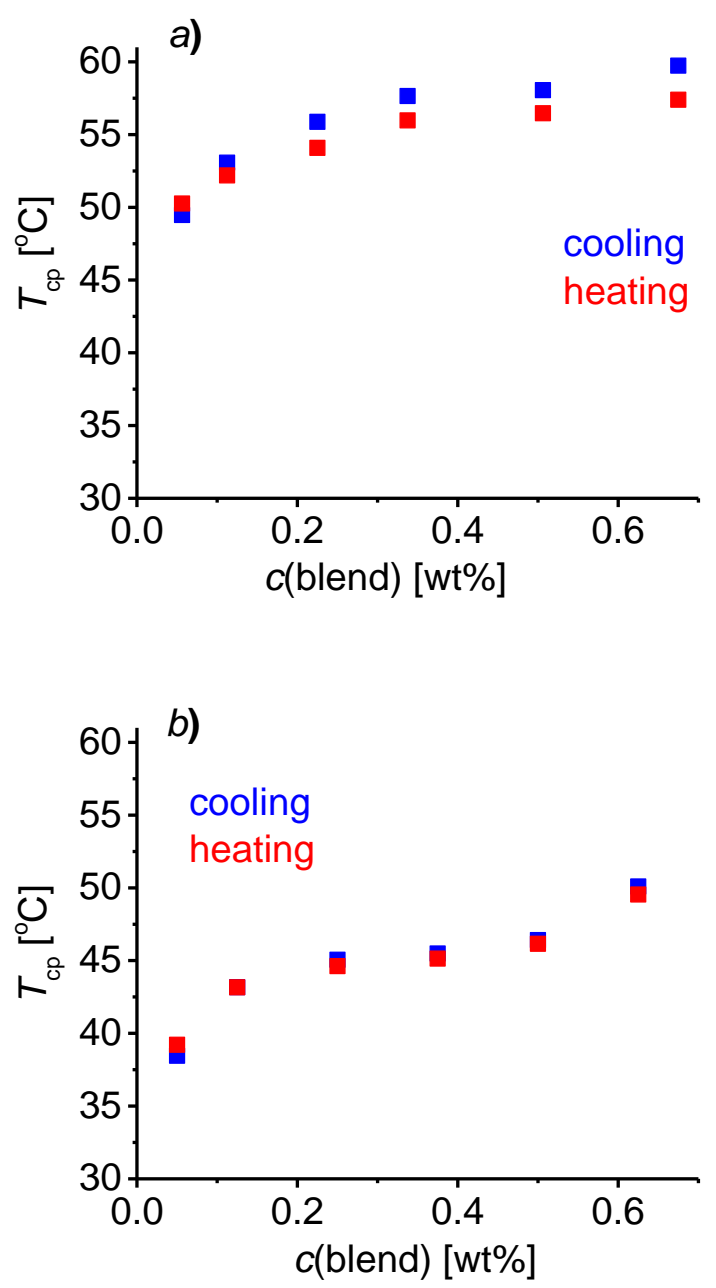

Figure 12. Cloud point temperatures of $\mathrm{PEG}^{6 \mathrm{k}}-\mathrm{PAA}^{10.7 \mathrm{k}}(a)$ and PPEGMA ${ }_{500}{ }^{9.9 \mathrm{k}}-\mathrm{PAA}^{10.7 \mathrm{k}}(b)$ solutions in isopropanol as a function of total polymer concentration at $n(\mathrm{EG}): n(\mathrm{AA})=1.3$ monomeric unit molar ratio

Increasing the concentration of polymers in PEG $^{6 \mathrm{k}}-\mathrm{PAA}^{10.7 \mathrm{k}}$ and $\mathrm{PPEGMA}_{500}{ }^{9.9 \mathrm{k}}-\mathrm{PAA}^{10.7 \mathrm{k}}$ mixed polymer solutions at the same polydonor:polyacceptor ratio results in increasing $T_{\mathrm{cp}}$, however, not in a linear way. In the range of 0.25-0.45 wt\% (Figure 12a and 12b), the graph indicates almost entirely concentration independence which tendency is similar to that of the 
PPEGMA homopolymers showing also increasing $T_{\mathrm{cp}}$ reaching a plateau with increasing polymer concentration. ${ }^{[11]}$ However, the observed steep increase in the higher concentration range indicates the presence of an additional phenomenon which might be related to the coupling of interpolymer complexes to each other which results in higher $T_{\mathrm{cp}}$.

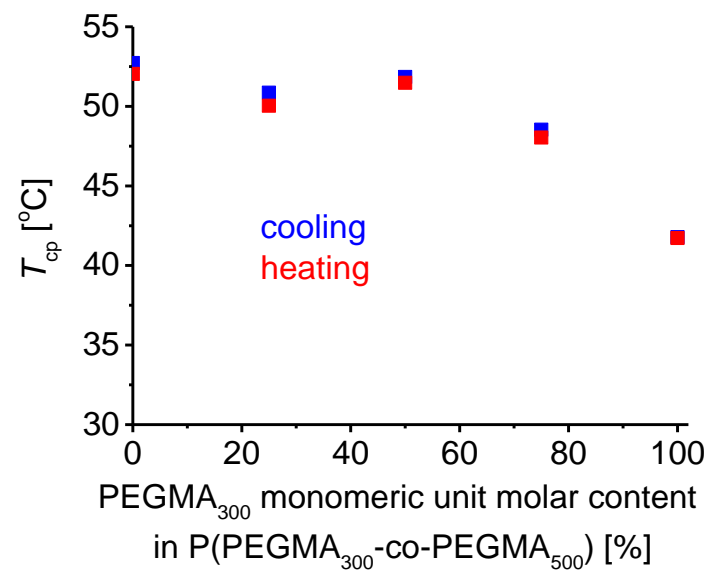

Figure 13. Cloud point temperatures of $\mathrm{P}\left(\mathrm{PEGMA}_{300}-\mathrm{co}-\mathrm{PEGMA}_{500}\right)-\mathrm{PAA}^{10.7 \mathrm{k}}$ solutions in isopropanol using $\mathrm{P}\left(\mathrm{PEGMA}_{300}-\right.$ co-PEGMA500) random copolymers with different average

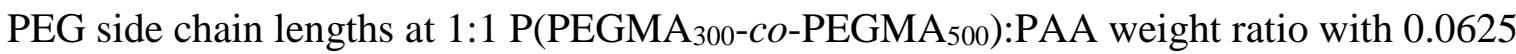
wt $\%$ PAA and $0.0625 \mathrm{wt} \% \mathrm{P}\left(\mathrm{PEGMA}_{300}-\mathrm{co}-\mathrm{PEGMA}_{500}\right)$ concentration

The effect of average PEG side chain length in PPEGMA on $T_{\mathrm{cp}}$ of PPEGMA-PAA mixed polymer solutions was also studied by varying the $\mathrm{PEGMA}_{300}$ content in $\mathrm{P}\left(\mathrm{PEGMA}_{300}-\mathrm{Co}\right.$ PEGMA500) random copolymers in the same molecular weight range, i.e. with $M_{\mathrm{n}}$ between 10 and $14 \mathrm{~kg} \mathrm{~mol}^{-1}$ (Table 1). Figure 13 shows that the $T_{\mathrm{cp}}$ of the PPEGMA $300^{10.4 \mathrm{k}}-\mathrm{PAA}^{10.7 \mathrm{k}}$ solution is lower than that of the PPEGMA $500^{10.1 \mathrm{k}}-\mathrm{PAA}^{10.7 \mathrm{k}}$ solution. This can be explained by the higher molar ratio of the methacrylate main chain in PPEGMA 300 related to PPEGMA 500 , on the one hand, and the possible different complex structure due to the shorter PEG side chains, on the other hand. Figure 13 also shows that the $T_{\mathrm{cp}}$ does not change considerably with increasing $\mathrm{PEGMA}_{300}$ content in the $\mathrm{P}\left(\mathrm{PEGMA}_{300}-\mathrm{co}-\mathrm{PEGMA}_{500}\right)$ random copolymers up to 
50 mol\% PEGMA 300 content, but a decreasing tendency is found above this composition range.

\section{Conclusions}

To summarize our results, it can be concluded that solutions of PEG:PAA polymer mixtures in isopropanol show reversible „UCST-type” thermoresponsive behaviour with a low extent of hysteresis. In the case of linear PEG homopolymers phase separation occurs at molecular weights higher than $1500 \mathrm{~g} \mathrm{~mol}^{-1}$ in the investigated temperature range and high hysteresis can be observed. The differences in the thermoresponsive behaviour of PEG-PAA systems related to PEG homopolymer solutions indicates that PEG-PAA interpolymer complexes precipitate below the cloud point temperature in isopropanol. Similar complex formation and „UCSTtype" thermoresponsiveness are also present in the solution of PPEGMA:PAA blends in isopropanol. The cloud point temperature for the mixed interpolymer solutions depends on molecular weight, EG:AA monomeric unit molar ratio, concentration and solvent nature. Increasing the ethylene glycol molar ratio or increasing the molecular weight of either the poly(acrylic acid) or the $\mathrm{H}$-acceptor polymer component of the interpolymer complex decreases the solubility and increases the cloud point temperatures of the interpolymer systems, resulting in a tunable phase behaviour. These findings may be utilized to explore novel intelligent material systems with well-defined UCST-type behaviour.

\section{Abbreviations}

PEG poly(ethylene glycol)

EG ethylene glycol (monomeric unit)

PAA poly(acrylic acid)

AA acrylic acid (monomeric unit) 
PEGMA poly(ethylene glycol) methacrylate

PPEGMA poly(poly(ethylene glycol) methacrylate)

$t$ BuA tert-butyl acrylate

HMTETA 1,1,4,7,10,10-hexamethyltriethylenetetraamine (HMTETA)

LCST lower critical solution temperature

UCST upper critical solution temperature

$T_{\mathrm{cp}}$ clouding point temperature

Acknowledgements: The authors thank Tamás Ignáth for his help in the gel permeation chromatography measurements and Dr. Amália Szanka for the purification of the $\mathrm{Cu}$-salts and toluene.

Keywords: poly(poly(ethylene glycol) methacrylate); poly(ethylene glycol); poly(acrylic acid); thermoresponsive behaviour; interpolymer complex

[1] V. R. de la Rosa, P. Woisel, R. Hoogenboom, Mater. Today, 2016, 19, 45-55.

[2] C. Heinzmann, C. Weder, L. Montero de Espinosa, Chem. Soc. Rev. 2016, 45, 342-358.

[3] S. Ishii, J. Kaneko, Y. Nagasaki, Macromolecules 2015, 48, 3088-3094.

[4] L. M. de Espinosa, G. L. Fiore, C. Weder, E. J. Foster, Y. C. Simon, Prog. Polym. Sci. 2015, 49-50, 60-78.

[5] V. V. Khutoryanskiy, Int. J. Pharm. 2007, 334, 15-26.

[6] D. M. Leite, E. Barbu, G. J. Pilkington, A. Lalatsa, Curr. Top. Med. Chem. 2015, 15, 2277 2289.

[7] M. A. Ward, T. K. Georgiou, Polymers 2011, 3, 1215-1242.

[8] E. Kharlampieva, V. Kozlovskaya, S. A. Sukhishvili, Adv. Mater. 2009, 21, 3053-3065.

[9] Y. Kohno, S. Saita, YJ. Men, JY. Yuan, H. Ohno, Polym. Chem. 2015, 6, 2163-2178. 
[10] A. Burkhart, H. Ritter, Beilstein J. Org. Chem. 2014, 10, 1951-1958.

[11] P. J. Roth, F. D. Jochum, P. Theato, Soft Matter 2011, 7, 2484-2492.

[12] P. J. Roth, T. P. Davis, A. B. Lowe, Macromolecules 2012, 45, 3221-3230.

[13] Q. Zhang, R. Hoogenboom, Prog. Polym. Sci. 2015, 48, 122-142.

[14] P. J. Roth, M. Collin, C. Boyer, Soft Matter 2013, 9, 1825-1834.

[15] C. Secker, A. Völkel, B. Tiersch, J. Koetz, H. Schlaad, Macromolecules 2016, 49, 979985.

[16] L. Mäkinen, D. Varadharajan, H. Tenhu, S. Hietala, Macromolecules 2016, 49, 986-993.

[17] H. Zhang, S. Guo, W. Fan, Y. Zhao, Macromolecules 2016, 49, 1424-1433.

[18] I. Gitsov, LL. Wang, N. Vladimirov, A. Simonyan, D. J. Kiemle, A. Schutz, Biomacromolecules 2014, 15, 4082-4095.

[19] F. E. Bailey, R. D. Lundberg, R. W. Callard, J. Polym. Sci., Part A 1964, 2, 845-851.

[20] A. D. Antipina, V. Y. Baranovsky, I. M. Papisov, V. A. Kabanov, Polym. Sci. USSR 1972, 14, 1047-1057.

[21] S. K. Chatterjee, N. Chatterjee, G. Riess, Makromolekulare Chemie - Macromol. Chem. Phys. 1982, 183, 481-487.

[22] E. Tsuchida, K. Abe, Adv. Polym. Sci. 1982, 45, 1-119.

[23] I. Iliopoulos, R. Audebert, Polym. Bull. 1985, 13, 171-178.

[24] B. Bednar, Z. Li, Y. Huang, L-C. P. Chang, H. Morawetz, Macromolecules 1985, 18, 18291833.

[25] I. Iliopoulos, R. Audebert, Eur. Polym. J. 1988, 24, 171-175.

[26] G. A. Mun, Z. S. Nurkeeva, V. V. Khutoryanskiy, A. D. Sergaziyev, Colloid Polym. Sci. 2002, 280, 282-289.

[27] G. A. Mun, Z. S. Nurkeeva, G. T. Akhmetkalieva, S. N. Shmakov, V. V. Khutoryanskiy, S. C. Lee, K. J. Park, Polym. Sci. Part B: Polym. Phys. 2006, 44, 195-204.

[28] F. Bian, M. Liu, Eur. Polym. J. 2003, 39, 1867-1874. 
[29] X. H. Lu, Z. B. Hu, J. Schwartz, Macromolecules 2002, 35, 9164-9168.

[30] K. Karayanni, G. Staikos, Eur. Polym. J. 2000, 36, 2645-2650.

[31] V. V. Khutoryanskiy, M. G. Cascone, L. Lazzeri, Z. S. Nurkeeva, G. A. Mun, R. A. Mangazbaeva, Polym. Int. 2003, 52, 62-67.

[32] QQ. Mao, K. Liu, W. Li, JT. Yan, AF. Zhang, Polym. Chem. 2015, 6, 1300-1308.

[33] B. Yeniad, K. Ryskulova, D. Fournier, J. Lyskawa, G. Cooke, P. Woisel, R. Hoogenboom, Polym. Chem. 2016, 7, 3681-3690.

[34] I. Suleimenov, O. Guven, G. A. Mun, A. Beissegul, S. Panchenko, R. Ivlev, Polym. Int. 2013, 62, 1310-1315.

[35] X. Pang, L. Zhao, M. Akinc, J. K. Kim, Z. Lin, Macromolecules 2011, 44, 3746-3752.

[36] Á. Szabó, Gy. Szarka, B. Iván, Macromol. Rapid Commun. 2015, 36, 238-248.

[37] Z. S. Nurkeeva, G. A. Mun, V. V. Khutoryanskiy, A. D. Sergaziyev, Eur. Polym. J. 2002, 38, 313-316.

[38] D. L. Ho, B. Hammouda, S. R. Kline, W-R. Chen, J. Polym. Sci. Part B: Polym. Phys. 2006, 44, 557-564.

\section{Figures}

a)

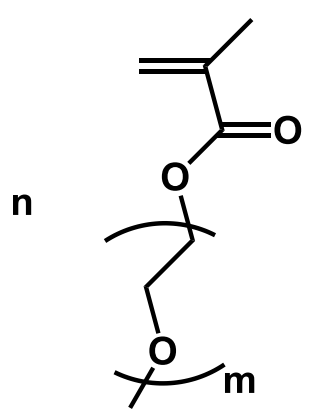

ethyl 2-bromoisobutyrate HMTETA / CuCl
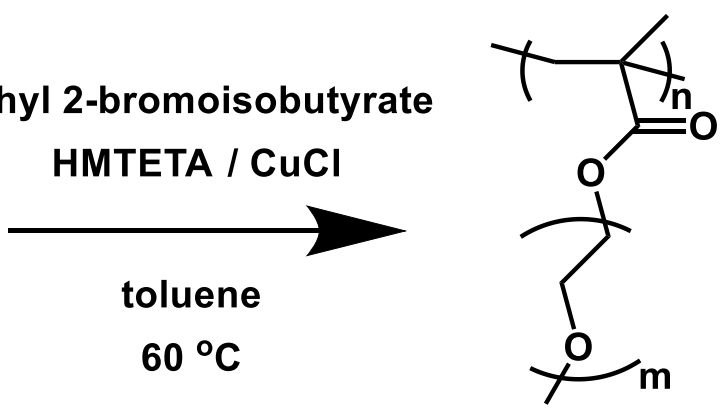

b)
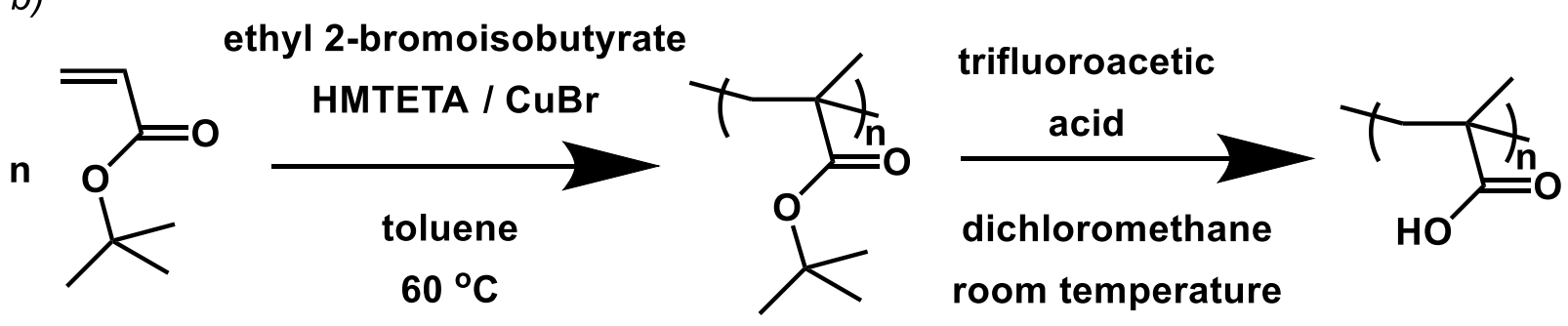
Figure 1. The scheme of the preparation of a) PPEGMA and b) PAA
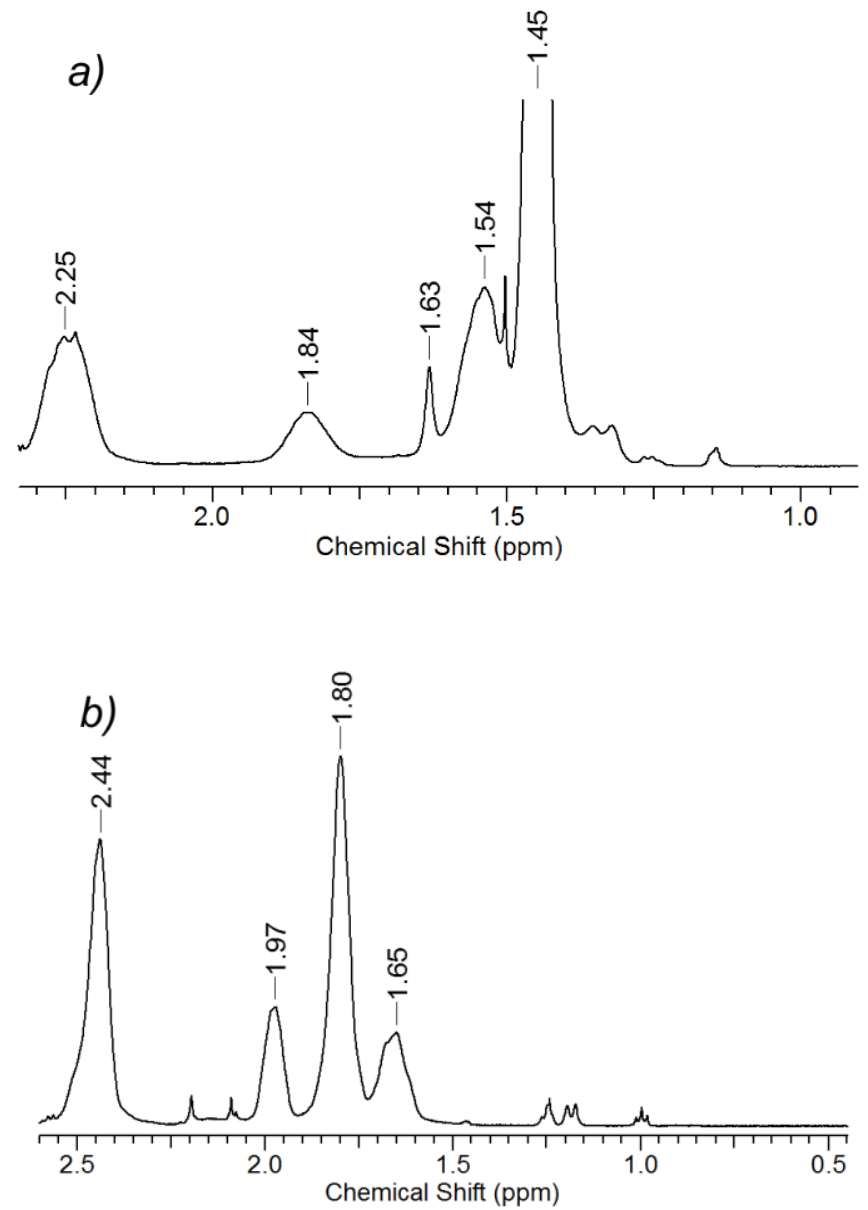

Figure 2. ${ }^{1} \mathrm{H}$ NMR spectra of $\mathrm{P} \mathrm{BuA}^{19.0 \mathrm{k}}$ in $\mathrm{CDCl}_{3}(a)$ and its hydrolyzed form $\mathrm{PAA}^{10.7 \mathrm{k}}$ in $\mathrm{D}_{2} \mathrm{O}(b)$ (peaks at $2.25 \mathrm{ppm}(a)$ and $2.44 \mathrm{ppm}(b)$ are the signals of the methine protons of the polyacrylate main chain, whereas peaks at $1.84 \mathrm{ppm}, 1.63$ and $1.54 \mathrm{ppm}(a)$ and at $1.97 \mathrm{ppm}$, $1.80 \mathrm{ppm}$ and $1.65 \mathrm{ppm}(\mathrm{b})$ belong to the methylene proton of the polyacrylate main chain)

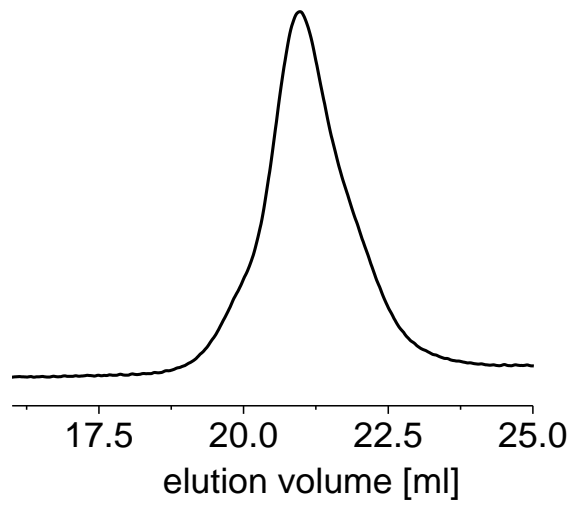

Figure 3. Gel permeation chromatogram of PPEGMA 5009 .9k 


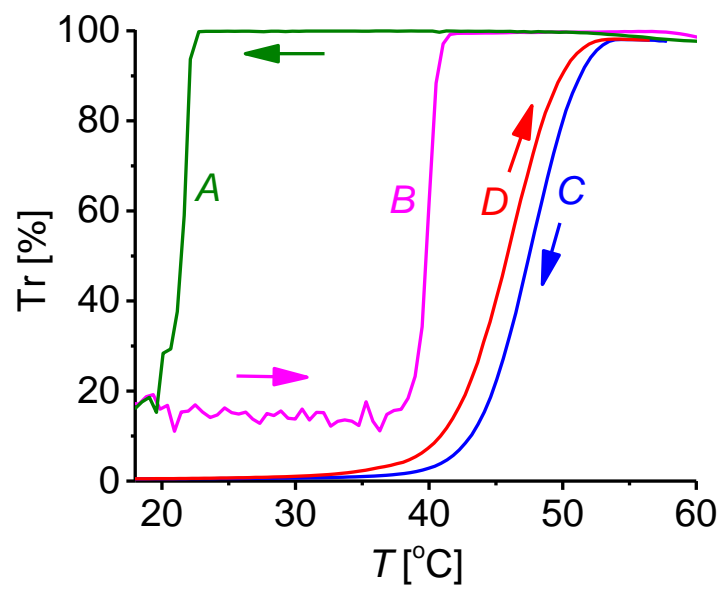

Figure 4. The transmittance (Tr) of $\mathrm{PEG}^{6 \mathrm{k}}$ homopolymer and $\mathrm{PEG}^{6 \mathrm{k}}{ }_{-} \mathrm{PAA}^{10.7 \mathrm{k}}$ solutions in isopropanol at $n(\mathrm{EG}): n(\mathrm{AA})=1.3$ monomeric unit molar ratio with $0.050 \mathrm{wt} \%$ PEG $(A$ and $B)$ and with $0.050 \mathrm{wt} \%$ PEG and $0.0625 \mathrm{wt} \%$ PAA $(C$ and $D)$ concentration as a function of temperature $\left(A\right.$ : $^{\text {PEG }}{ }^{6 \mathrm{k}}$ cooling, $B$ : $\mathrm{PEG}^{6 \mathrm{k}}$ heating, $C$ : $\mathrm{PEG}^{6 \mathrm{k}}-\mathrm{PAA}^{10.7 \mathrm{k}}$ cooling, $D$ : $\mathrm{PEG}^{6 \mathrm{k}}-$

$\mathrm{PAA}^{10.7 \mathrm{k}}$ heating; the arrows indicate the direction of temperature change)

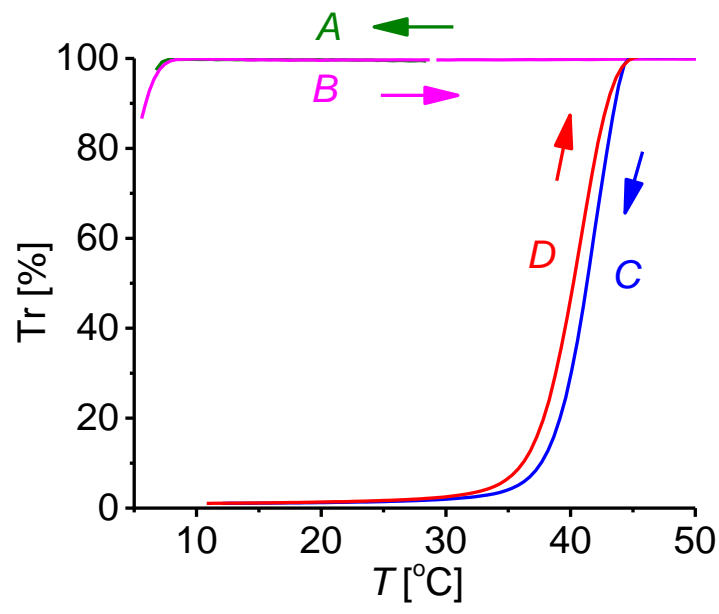

Figure 5. The transmittance $(\mathrm{Tr})$ of PPEGMA ${ }_{500}{ }^{9.9 \mathrm{k}}$ homopolymer and

PPEGMA $_{500} 9.9 \mathrm{k}_{-} \mathrm{PAA}^{10.7 \mathrm{k}}$ solutions in isopropanol at $n(\mathrm{EG}): n(\mathrm{AA})=1.3$ monomeric unit molar ratio with $0.0625 \mathrm{wt} \%$ PPEGMA $(A$ and $B)$ and with $0.0625 \mathrm{wt} \%$ PPEGMA and 0.0625 wt $\%$ PAA $(C$ and $D)$ concentration as a function of temperature $(A$ : PPEGMA $500.9 \mathrm{k}$ cooling, $B$ : PPEGMA $500^{9.9 \mathrm{k}}$ heating, $C$ : PPEGMA $500^{9.9 \mathrm{k}}-\mathrm{PAA}^{10.7 \mathrm{k}}$ cooling, $D$ : PPEGMA $500{ }^{9.9 \mathrm{k}}$-PAA $^{10.7 \mathrm{k}}$ heating; the arrows indicate the direction of temperature change) 

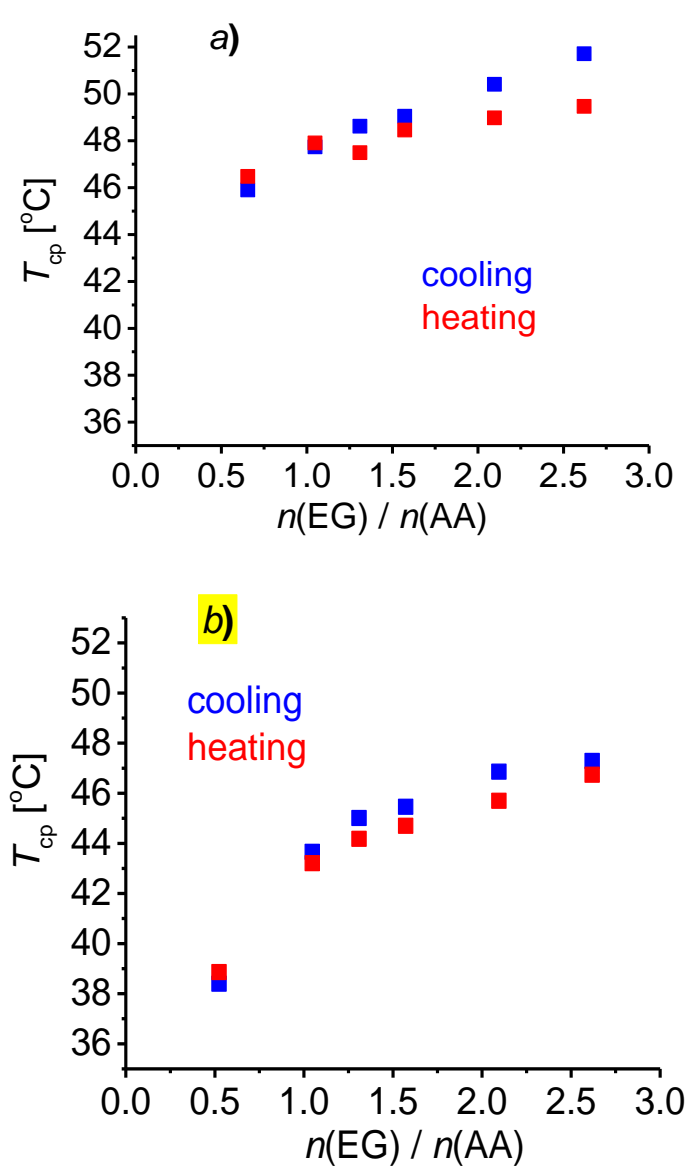

Figure 6. Cloud point temperatures of $\mathrm{PEG}^{6 \mathrm{k}}{ }_{-} \mathrm{PAA}^{10.7 \mathrm{k}}(a)$ and $\mathrm{PPEGMA}_{500}{ }^{9.9 \mathrm{k}}-\mathrm{PAA}^{10.7 \mathrm{k}}(b)$ solutions in isopropanol as a function of EG:AA monomeric unit molar ratios with 0.0625 wt $\%$ PAA concentration

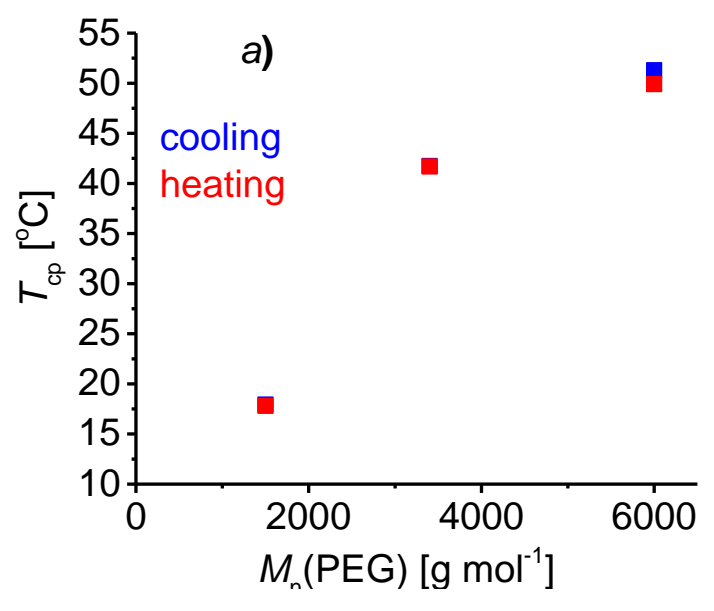




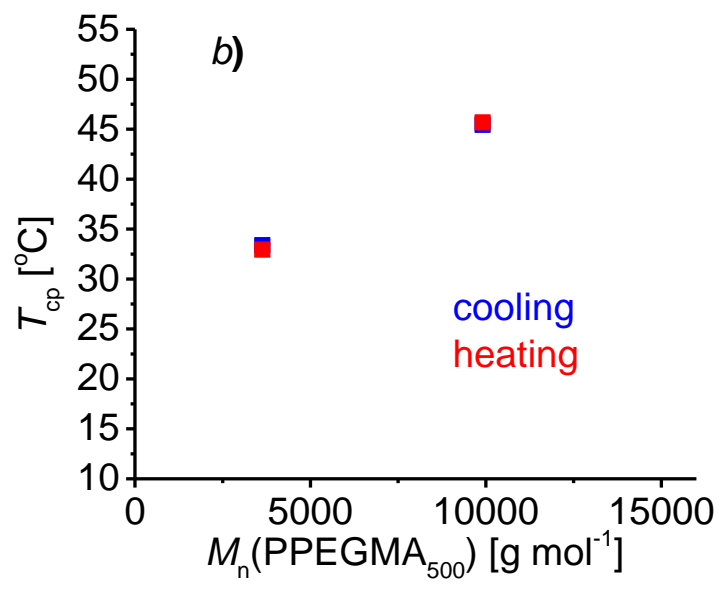

Figure 7. Cloud point temperatures of PEG-PAA ${ }^{10.7 \mathrm{k}}(a)$ and PPEGMA $500-\mathrm{PAA}^{10.7 \mathrm{k}}(b)$ solutions in isopropanol as a function of PEG $(0.05 \mathrm{wt} \%)(a)$ or PPEGMA $(0.0625 \mathrm{wt} \%)(b)$ molecular weights at $n(\mathrm{EG}): n(\mathrm{AA})=1.3$ monomeric unit molar ratio with $0.0625 \mathrm{wt} \%$ PAA concentration
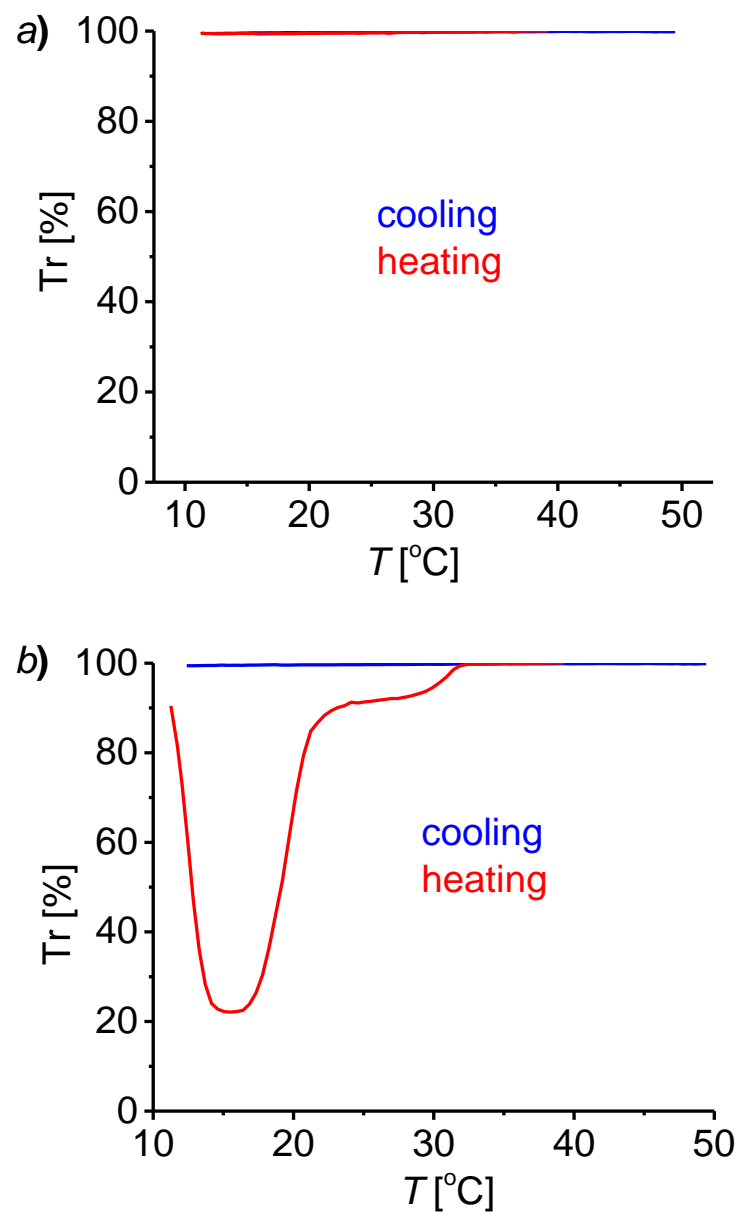

Figure 8. The transmittance (Tr) of $\mathrm{PEG}^{0.6 \mathrm{k}}(a)$ and $\mathrm{PEG}^{1.5 \mathrm{k}}(b)$ homopolymer solutions in isopropanol as a function of temperature $(0.05 \mathrm{wt} \%$ PEG concentration) 


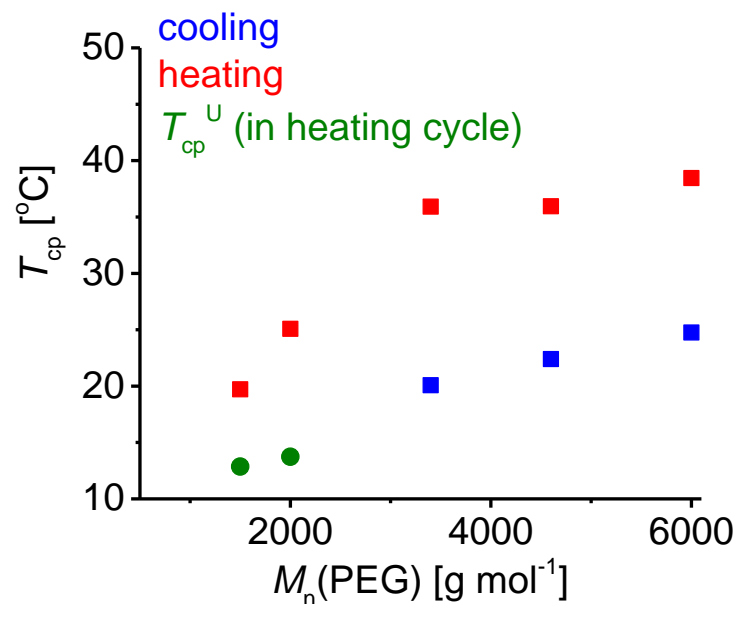

Figure 9. Cloud point temperatures of PEG homopolymer solutions with different molecular weights in isopropanol (0.05 wt\% PEG concentration)
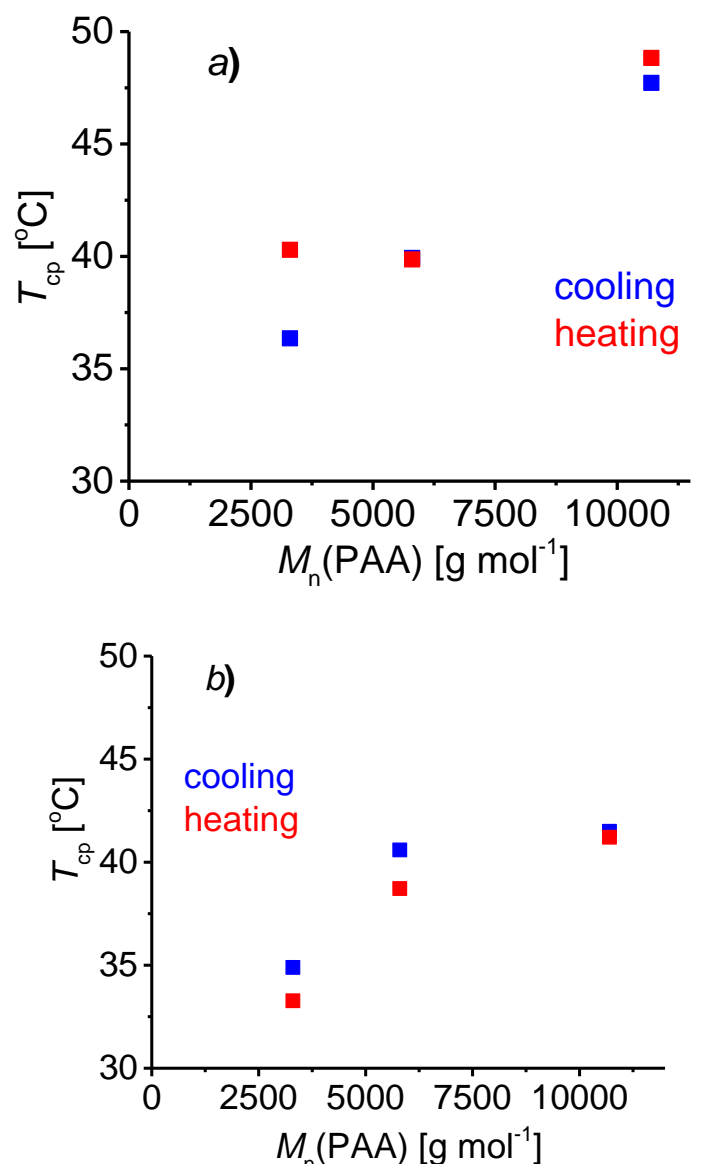

Figure 10. Cloud point temperatures of PEG ${ }^{6 \mathrm{k}}$-PAA $(a)$ and PPEGMA $500{ }^{9.9 \mathrm{k}}$-PAA $(b)$ solutions in isopropanol as a function of PAA molecular weights at $n(\mathrm{EG}): n(\mathrm{AA})=1.3$ monomeric unit molar ratio with $0.0625 \mathrm{wt} \%$ PAA and $0.05 \mathrm{wt} \%$ PEG $(a)$ or $0.0625 \mathrm{wt} \%$ PPEGMA $_{500}(b)$ concentration 

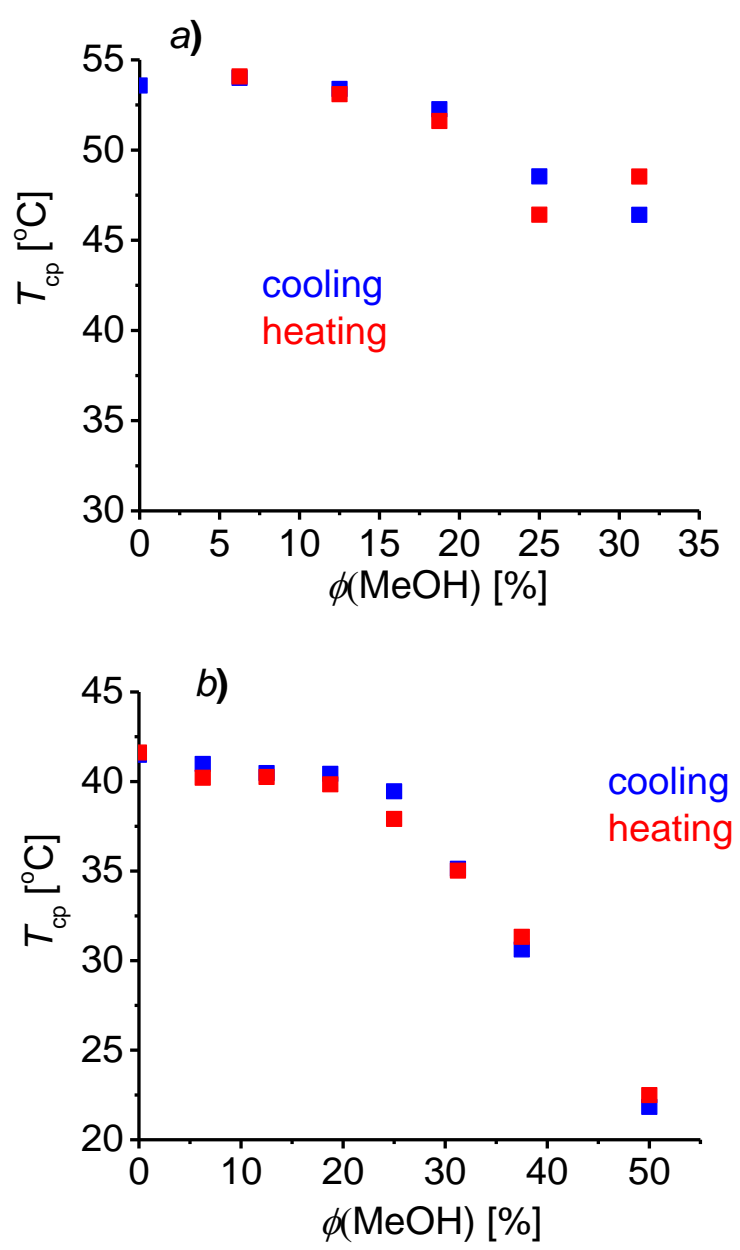

Figure 11. Cloud point temperatures of PEG ${ }^{6 \mathrm{k}}-\mathrm{PAA}^{10.7 \mathrm{k}}(a)$ and PPEGMA $500{ }^{9.9 \mathrm{k}}-\mathrm{PAA}^{10.7 \mathrm{k}}(b)$ solutions in isopropanol/methanol solvent mixtures as a function of methanol volume fraction $(\Phi(\mathrm{MeOH}))$ at $n(\mathrm{EG}): n(\mathrm{AA})=1.3$ monomeric unit molar ratio with $0.0625 \mathrm{wt} \% \mathrm{PAA}$ and $0.05 \mathrm{wt} \%$ PEG $(a)$ or $0.0625 \mathrm{wt} \%$ PPEGMA $500(b)$ concentration

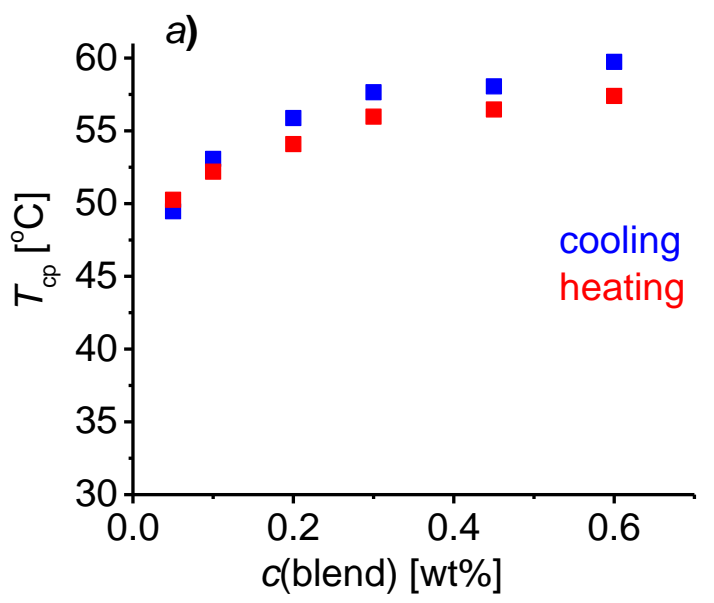




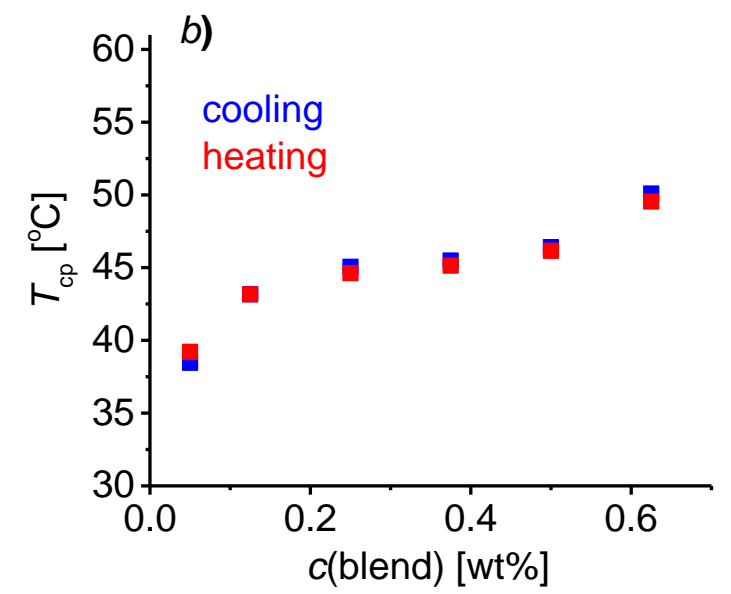

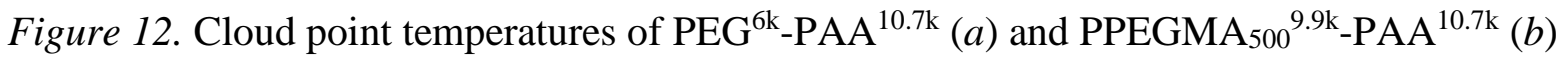
solutions in isopropanol as a function of total polymer concentration at $n(\mathrm{EG}): n(\mathrm{AA})=1.3$ monomeric unit molar ratio

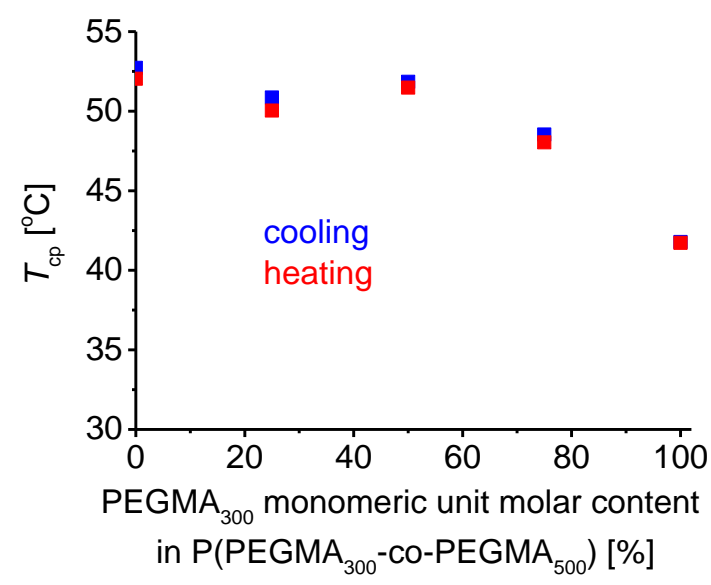

Figure 13. Cloud point temperatures of $\mathrm{P}\left(\mathrm{PEGMA}_{300}\right.$-co-PEGMA $\left.{ }_{500}\right)-\mathrm{PAA}^{10.7 \mathrm{k}}$ solutions in isopropanol using $\mathrm{P}\left(\mathrm{PEGMA}_{300}-c o-\mathrm{PEGMA}_{500}\right)$ random copolymers with different average PEG side chain lengths at 1:1 P(PEGMA $300-c o-P E G M A 500): P A A$ weight ratio with 0.0625 wt $\%$ PAA and $0.0625 \mathrm{wt} \% \mathrm{P}\left(\mathrm{PEGMA}_{300}-\mathrm{co}-\mathrm{PEGMA}_{500}\right)$ concentration

Table 1. The molar compositions of PEGMA 500 and PEGMA 300 in the feed for the synthesis of PPEGMA homopolymers and copolymers, and the number average molecular weights $\left(M_{\mathrm{n}}\right)$ and polydispersity indices $\left(M_{\mathrm{w}} / M_{\mathrm{n}}\right)$, determined by gel permeation chromatography, of the resulting PPEGMAs

\begin{tabular}{|c|c|c|c|}
\hline $\begin{array}{c}\text { PEGMA500 } \\
\text { monomeric } \\
\text { unit molar } \\
\text { content } \\
{[\%]}\end{array}$ & $\begin{array}{c}\text { PEGMA300 } \\
\text { monomeric } \\
\text { unit molar } \\
\text { content } \\
{[\%]}\end{array}$ & $\begin{array}{c}\boldsymbol{M}_{\mathbf{n}}(\mathbf{G P C}) \\
{\left[\mathbf{g} \mathbf{~ m o l}^{-1}\right]}\end{array}$ & $\begin{array}{c}\boldsymbol{M}_{\mathbf{w}} / \\
\boldsymbol{M}_{\mathbf{n}}\end{array}$ \\
\hline 100 & 0 & 3600 & 1.70 \\
\hline 100 & 0 & 9900 & 1.18 \\
\hline 100 & 0 & 10100 & 1.11 \\
\hline 75 & 25 & 10900 & 1.13 \\
\hline
\end{tabular}




\begin{tabular}{|c|c|c|c|}
\hline 50 & 50 & 12700 & 1.11 \\
\hline 25 & 75 & 13800 & 1.20 \\
\hline 0 & 100 & 10400 & 1.34 \\
\hline
\end{tabular}

